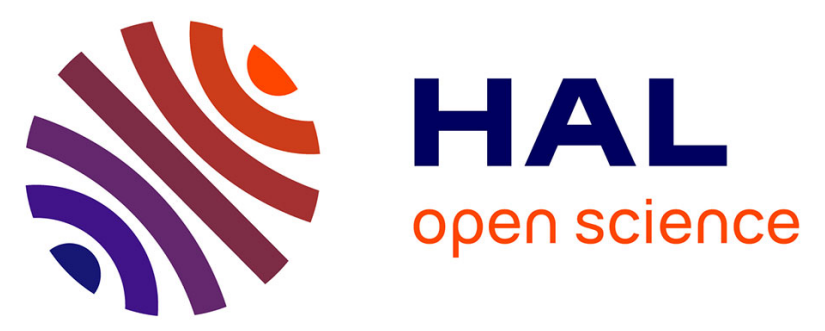

\title{
Catalytic Enantioselective Desymmetrization of Meso Compounds in Total Synthesis of Natural Products: Towards an Economy of Chiral Reagents
}

\author{
Jérémy Mérad, Mathieu Candy, Jean-Marc Pons, Cyril Bressy
}

\section{To cite this version:}

Jérémy Mérad, Mathieu Candy, Jean-Marc Pons, Cyril Bressy. Catalytic Enantioselective Desymmetrization of Meso Compounds in Total Synthesis of Natural Products: Towards an Economy of Chiral Reagents. Synthesis: Journal of Synthetic Organic Chemistry, 2017, 49 (09), pp.1938-1954. 10.1055/s-0036-1589493 . hal-01687264

\section{HAL Id: hal-01687264 https://hal.science/hal-01687264}

Submitted on 18 Jan 2018

HAL is a multi-disciplinary open access archive for the deposit and dissemination of scientific research documents, whether they are published or not. The documents may come from teaching and research institutions in France or abroad, or from public or private research centers.
L'archive ouverte pluridisciplinaire HAL, est destinée au dépôt et à la diffusion de documents scientifiques de niveau recherche, publiés ou non, émanant des établissements d'enseignement et de recherche français ou étrangers, des laboratoires publics ou privés. 


\section{Catalytic Enantioselective Desymmetrization of Meso Compounds in Total Synthesis of Natural Products: Towards an Economy of Chiral Reagents}

\author{
Jérémy Merad ${ }^{1}$ \\ Mathieu Candy \\ Jean-Marc Pons \\ Cyril Bressy* \\ Aix Marseille Univ, CNRS, Centrale Marseille, iSm2, \\ Marseille, France \\ cyril.bressy@univ-amu.fr \\ In memory of our friend and colleague, Professor \\ Teodor Silviu Balaban
}

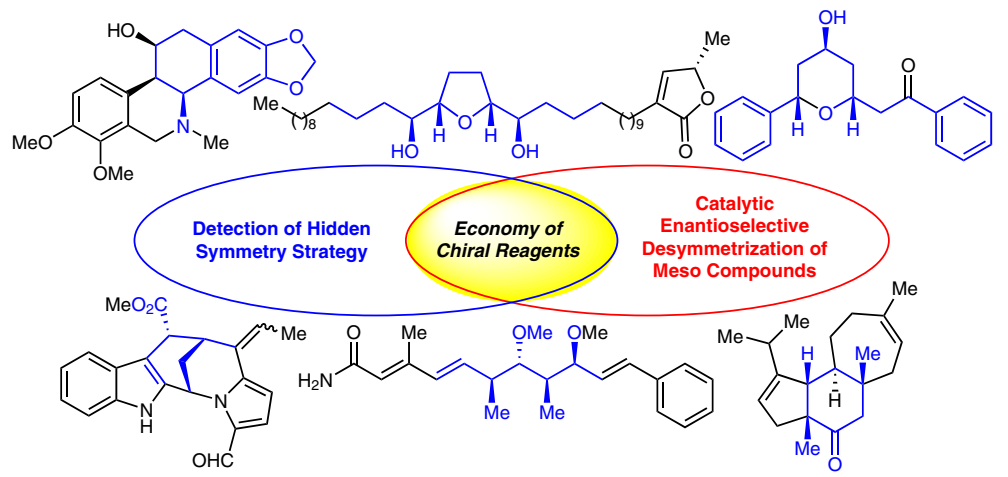

Received: 20.02.2017

Accepted: 28.02.2017

Published online: 23.03 .2017

DOI: 10.1055/s-0036-1589493; Art ID: ss-2017-z0105-sr

Abstract Meso compounds represent a particular family of achiral molecules bearing elements of chirality. Their desymmetrization through enantioselective catalytic methods usually leads to elaborate chiral building blocks containing several stereogenic elements, which can be a very useful and elegant approach in the context of total synthesis. In the present review, the power of this strategy is illustrated through the different possibilities of catalytic enantioselective desymmetrization. From the combination of the hidden symmetry detection and the catalytic enantioselective transformations a new type of economy emerges: the economy of chiral reagents.

1 Introduction

1.1 What Is a Meso Compound?

1.2 Why Is the Catalytic Enantioselective Desymmetrization of Meso Compounds a Powerful Strategy in Total Synthesis?

1.3 Toward an Economy of Chiral Reagents

2 Enzymatic Desymmetrization

2.1 (-)-Sceptrin (Baran, 2006)

2.2 cis-Solamin (Stark, 2006)

2.3 Crocacin C (2010, Bressy/Pons)

3 Metallocatalyzed Desymmetrization

3.1 Quadrigemine C (2002, Overman)

3.2 (+)-Homochelidonine (2007, Lautens)

3.3 (-)-Cyanthiwigin F (2008, Stoltz)

3.4 [5]-Ladderanoic Acid (2016, Gonzalez-Martinez/Boxer/Burns)

4 Organocatalyzed Desymmetrization

4.1 (+)-Hirsutene (2008, List)

4.2 Alstoscholarines (2011, Neuville/Zhu)

4.3 (-)-Diospongin A (2015, Chuzel/Bressy)

5 Conclusion

Key words total synthesis, natural product, meso compounds, desymmetrization, enantioselective catalysis, economy of chiral reagents, hidden symmetry, amplification

\section{Introduction}

\subsection{What Is a Meso Compound?}

Symmetry is a fascinating aspect of matter, which can be admired in vegetal and animal reigns of Nature. It also influences, as a stimulating concept, human creativity in the arts, like painting, sculpture, or even literature (one of the longest palindromes, a highly symmetrical sentence, was written by Georges Pérec). ${ }^{2}$ Symmetry is also a fundamental concept in various fields of science like mathematics, physics, or chemistry. Molecular symmetry can be classified, according to group theory, through different elements of symmetry. ${ }^{3}$ Among achiral molecules, prochiral and meso compounds can be distinguished. These both types of achiral molecules can become chiral in a single desymmetrization step. Prochiral molecules can be subdivided into trigonal systems, such as carbonyls or alkenes with enantiotopic faces (Scheme 1, a), and tetrahedral systems where an $\mathrm{sp}^{3}$ atom, the prostereogenic center, bears two enantiotopic groups (Scheme 1, b). A meso molecule has been defined by IUPAC as 'an achiral member(s) of a set of diastereomers which also includes one or more chiral members'. ${ }^{4}$ With this definition, it is difficult to visualize which reality it may cover. Unlike prochiral molecules, meso compounds contain pair(s) of stereogenic elements (central, axial, planar, or helical), but remain achiral due to the presence of a symmetry element, a plan of symmetry $\sigma\left(S_{1}\right)$, an inversion point $\mathrm{i}\left(S_{2}\right)$, or an improper axis of symmetry $\left(S_{\mathrm{n}}\right)$ (Scheme 1, c). 


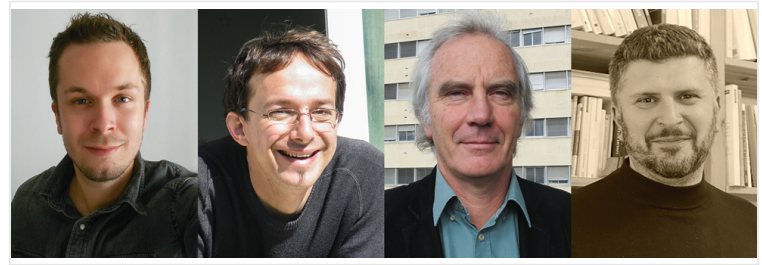

Jérémy Merad received his Bachelor of Science at the Université de Toulon before moving to the Université de Montpellier to obtain his Master of Science with Dr. Camille Oger and Dr. Jean-Marie Galano working on the synthesis of neuroprostanes. In 2015 he completed his Ph.D. under the supervision of Prof. Jean-Marc Pons and Prof. Cyril Bressy at Aix-Marseille Université. His thesis focused on the preparation of acyclic 1,3-diols using chiral isothioureas and involving enantioselective amplification processes. At the beginning of 2016 he joined the group of Prof. Nuno Maulide in Vienna, Austria as postdoctoral researcher.

Mathieu Candy studied at the Aix-Marseille Universite (AMU) where he obtained his Ph.D. in 2010 under the supervision of Prof. Jean-Marc Pons and Prof. Cyril Bressy. His thesis topic focused on hidden symmetry in total synthesis using desymmetrization of meso diols. He then joined the group of Prof. Dr. Carsten Bolm in Aachen, Germany as a Humboldt post-doctoral researcher, where he worked on the chemistry of sulfondiimines. Back in France, he joined the group of Prof. J. M. Campagne and then Dr. T. Durand, both in Montpellier, as a postdoctoral researcher working on the total synthesis of natural products. He is now completing an industrial project in Toulouse, France in the group of Dr. Y. Genisson.

Jean-Marc Pons studied at the Université de Provence in Marseille where he obtained his Ph.D. in 1982 under the supervision of Prof. Maurice Santelli. He then entered the CNRS as Chargé de Recherches and defended a Thèse d'Etat in 1987 on low valent transition metal complexes in organic synthesis. In 1988 , he spent a year as a postdoctoral fellow in the group of Prof Philip Kocienski in Southampton, where he worked on natural product total synthesis. Back in Marseille, he was appointed professor at Aix-Marseille Université in 1999. He is currently involved in organocatalyzed transformations, and is also dean of the faculty of sciences of Aix-Marseille Université.

Cyril Bressy studied at the Université Claude Bernard in Lyon where he obtained his Ph.D. in 2004 under the supervision of Prof. Olivier Piva He then joined, as post-doctoral researcher, the group of the Prof. Mark Lautens in Toronto, Canada where he developed a novel variant of the Catellani reaction. Back in France, he worked on a total synthesis project in Paris at Ecole Supérieure de Physique et Chimie Industrielle (ESP CI-ParisTech) with Prof. Janine Cossy. In 2006 he held the position of Maître de Conférences at Aix-Marseille Université (AMU). In 2012 he obtained a Habilitation à Diriger les Recherches (HDR) and was promoted as full Professor in 2015 at AMU. His research focuses on total synthesis using desymmetrization strategies and organocatalyzed transformations.

It is noteworthy that much confusion does exist in literature between prochiral and meso compounds probably due to the fact that they both incorporate enantiotopic positions. The confusion is also enhanced by the fact that a meso compound may bear a prostereogenic center. We propose to distinguish meso compounds without prostereogenic center from meso compounds with prostereogenic center(s) into Type I/Type II categories, respectively (Scheme 1, d).

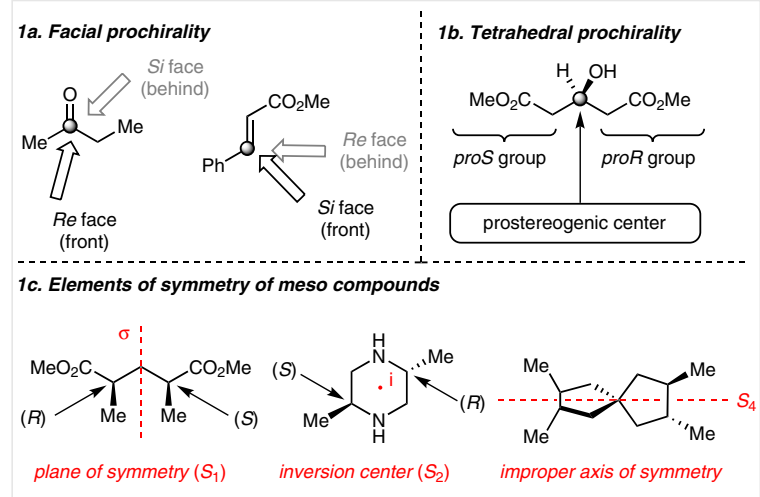

1d. Type I/ Type II categories of meso compounds

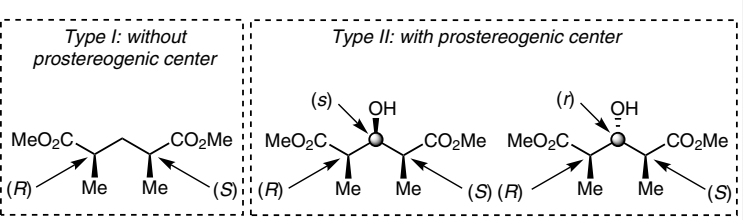

Scheme 1 Prochiral and meso compounds

The distinction between prochiral and meso compounds is a crucial aspect of the desymmetrization step, which is defined as a decrease in the number of symmetric elements. Indeed, while the desymmetrization of prochiral molecules leads to the creation of a stereogenic center in place of the previous prostereogenic center, the desymmetrization of meso compounds 'reveals' their pre-existing stereogenic elements.

\subsection{Why Is the Catalytic Enantioselective De- symmetrization of Meso Compounds a Powerful Strategy in Total Synthesis?}

Chiral compounds constitute, in general, the most expensive reagents of a synthetic sequence. Because of the additional difficulty that the preparation of perfectly stereodefined molecules represents, enantioenriched compounds are among the most expensive in a synthetic sequence. Consequently, the use of stoichiometric amounts of such molecules as substrates (chiral pool) or reagents appears financially unfavorable. Moreover from an eco-compatible point of view, the use of chiral reagents bearing a chiral moiety that is not embedded in the final target molecule results in expensive waste. Enantioselective catalysis circumvents these drawbacks enabling the use a small amount of chiral catalyst. Hence, coupled with enantioselective catalysis, the desymmetrization of meso compounds ${ }^{5}$ appear then as a clever strategy. Indeed complex chiral building blocks with several stereogenic elements can be prepared in a single enantioselective step using this strategy. 
In the context of total synthesis these types of building blocks prove to be highly useful to rapidly reach the molecular complexity encountered in natural products. This requires detecting, within the structure of the target, a local ${ }^{6}$ or hidden symmetry that may be exploited to introduce a highly symmetrical intermediate into the synthetic plan, which could be a meso compound. Practically, this strategy changes the sense of the stereocontrol during the synthesis. Indeed in the classical approach the enantiocontrol precedes the diastereocontrol (Scheme 2, a), while in the hidden symmetry approach, the diastereocontrol precedes the enantiocontrol (Scheme 2, b). Hence, this strategy offers the possibility of a late-stage desymmetrizing enantioselective step. The preparation of the meso intermediate requires a high level of diastereocontrol before the enantioselective desymmetrization step occurs. It is important to mention that the 'Meso Trick' can be extremely efficient in a synthetic sequence if the preparation of the meso intermediate is not demanding.

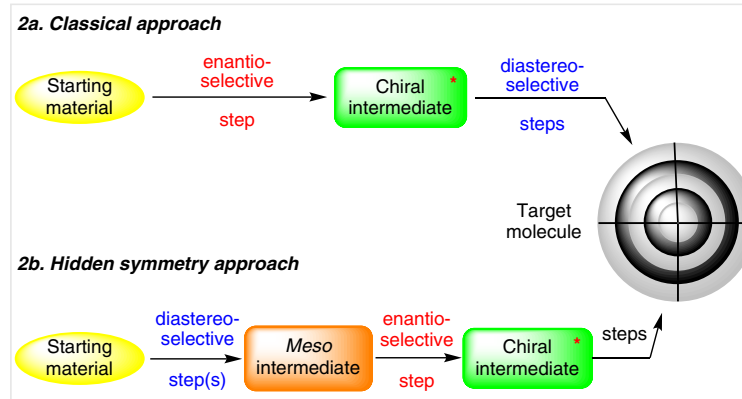

Scheme 2 Classical and hidden symmetry approaches in enantioselec tive synthesis

Another possible advantage to employ the catalytic enantioselective desymmetrization of meso compounds is the possible benefit offered by Horeau-type amplifications. ${ }^{8}$ Two scenarios can be involved, but in both situations meso intermediates generally present at least two enantiotopic reactive functional groups due to their symmetry.

The first possible scenario occurs when the enantiotopic functional groups are directly borne on the pre-existing stereogenic centers (Scheme 3). No additional stereocenter is created in this case. Here a desymmetrization and a kinetic resolution work in synergy. A first enantioselective transformation leads to the production of major and minor enantiomers. In the minor enantiomer, the fast reacting enantiotopic position, which has remained intact, undergoes a fast selective transformation leading to the production of a symmetrical byproduct. The transformation of the minor enantiomer in a sacrificial meso byproduct results in the improvement of the enantiomeric excess. In some cases the level of enantioselectivity can be particularly enhanced. ${ }^{9}$ The complete double reaction is not desirable because the resulting product is a meso compound. We qualified the kinetic resolution step as a chiroablative ${ }^{10}$ step since the chirality of the minor enantiomer is deleted through the second transformation, which leads to an achiral sacrificial byproduct.

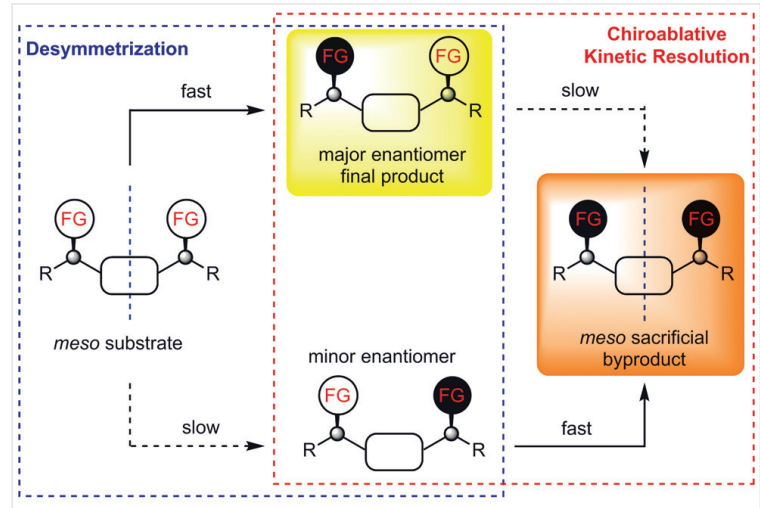

O pre-existing stereocenter

Scheme 3 Horeau amplification of enantioselectivity during the desymmetrization of meso compounds in the case of no creation of additional stereocenters

In the second possible scenario, the meso compound presents at least two functional groups with facial prochirality in addition to the pre-existing stereogenic centers (Scheme 4). ${ }^{\text {gg.h }}$ The catalytic enantioselective reaction transforms one of these two positions producing major $\mathbf{A}$ and minor ent-A enantiomers through the creation of a new stereocenter. Then the major enantiomer $\mathbf{A}$ can undergo a second diastereoselective transformation leading either to an ultra major enantiomer B (due to a second sorting) or a sacrificial meso compound $\mathbf{C}$. The same situation appears for the minor enantiomer ent-A, which can be transformed either into a meso compound $\mathbf{D}$ or into the ultra minor enantiomer ent-B. In brief, a synergy between desymmetrization and kinetic resolution leads to enantioselectivity amplification of the global transformation.

\subsection{Toward an Economy of Chiral Reagents}

From the combination of the hidden symmetry detection strategy and the catalytic enantioselective desymmetrization of meso compounds, a new type of economy emerges: the economy of chiral reagents. This latter can be added to the previous economies of atoms, ${ }^{11}$ steps, ${ }^{12}$ and redox steps. ${ }^{13}$ As mentioned previously, the cost of optically active chiral reagents is potentially very high. The control of the different stereogenic elements of a complex target can require the use of several chiral reagents, especially when the target molecule is acyclic, since no cyclic stereocontrol can be involved. Indeed, the substrate-control may not be sufficiently diastereoselective leading to the necessary use of a chiral reagent to ensure, via reagent-control, better ste- 


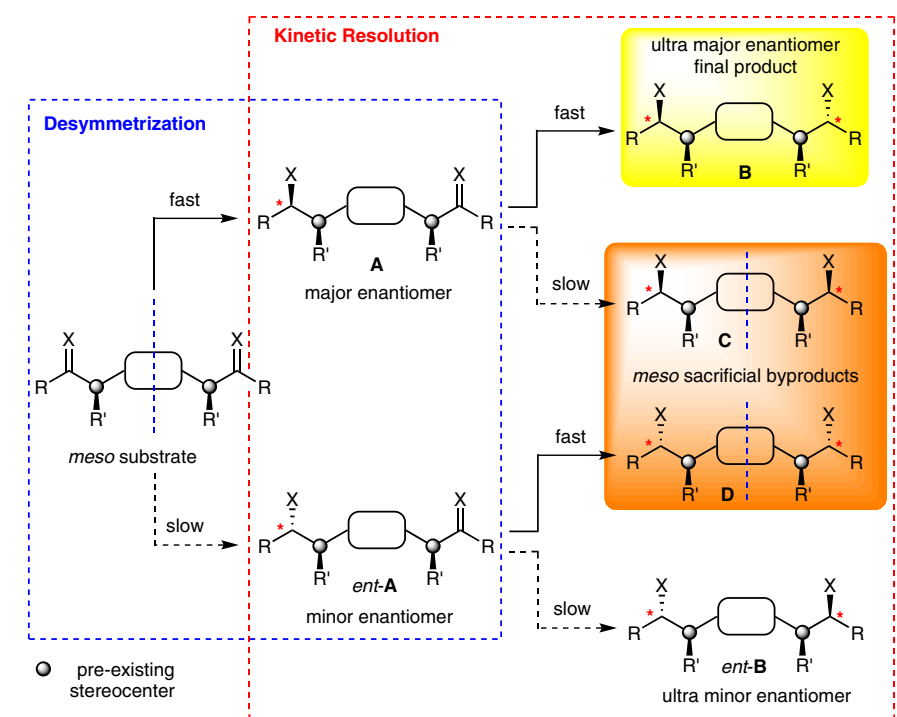

Scheme 4 Horeau amplification of enantioselectivity during the desymmetrization of meso compounds in the case of the creation of additional stereocenters

reocontrol. The simultaneous stereocontrol of several stereogenic elements obtained in the catalytic enantioselective desymmetrization of meso intermediates is an interesting strategy that avoids the extensive use of chiral reagents.

The present review aims to illustrate, through significant and recent total syntheses of natural products from various classes (terpenes, polyketides, alkaloids) described between 2002 and 2016, the power of catalytic enantioselective desymmetrization of meso compounds to achieve an economy of chiral reagents. The review is organized according to the type of catalysis involved in the enantioselective desymmetrization key step.

\section{Enzymatic Desymmetrization}

Historically, and in term of popularity, enzymatic transformation was the first explored catalytic approach to desymmetrize meso compounds. ${ }^{5 \mathrm{~d}}$ Transesterifications, hydrolysis of esters, and some oxidations are the predominant reactions involved in the desymmetrization of meso substrates. The catalytic enzymatic process is extremely interesting due to the mildness of the conditions and the high selectivity often obtained.

\section{1 (-)-Sceptrin (Baran, 2006)}

(-)-Sceptrin, isolated in 1981 from Agelas sceptrum by Faulkner and Clardy, ${ }_{1}^{14}$ presents a wide range of biological activities (antibacterial, antiviral, antihistaminic, etc.). The biosynthetic route seems to involve a dimerization through a [2+2] photocycloaddition, despite the fact that this natural product was found in ocean depths. In 2004, the Baran group described its total synthesis in racemic series..$^{15}$ Two years later, the same group published the enantioselective version still starting from the meso cycloadduct 1 obtained through the reaction between 2,5-dimethylfuran and dimethyl acetylenedicarboxylate (Scheme 5). ${ }^{16}$ After the desymmetrization of meso compound 1 the oxabicyclic structure is rearranged under photochemical conditions to afford the tetrasubstituted cyclobutane. ${ }^{17}$

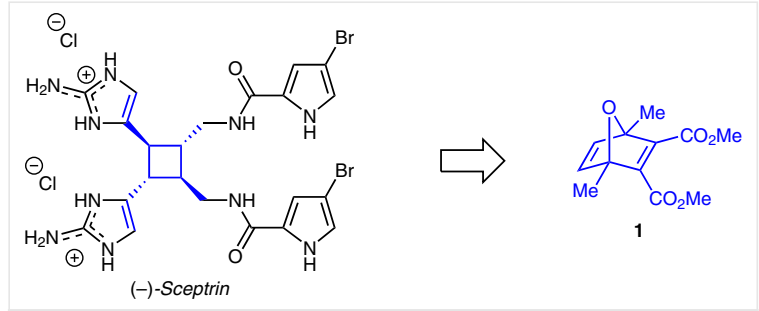

Scheme 5 Baran's retrosynthetic plan for (-)-sceptrin

The synthesis began with the hydrolytic desymmetrization of meso compound $\mathbf{1}$ using pig liver esterase (PLE) to obtain carboxylic acid $\mathbf{2}$ in quantitative yield, but modest enantiomeric excess (Scheme 6). Oxabicycle $\mathbf{2}$ was then esterified with isopropyl alcohol using 4-(4,6-dimethoxy1,3,5-triazin-2-yl)-4-methylmorpholinium chloride (3) before being converted into the corresponding amide in two 
steps. Amide $\mathbf{4}$ was submitted to photochemical conditions that promoted an intramolecular $[2+2]$ photocycloaddition leading to the formation of oxaquadricyclane $\mathbf{5}$. This then underwent fragmentation under acidic conditions (following the red bonds) leading to bicyclic carbocation 6 . The later intermediate allowed the production of cyclobutane $\mathbf{7}$ by addition of water and a final fragmentation (following the red bond). It is noteworthy to mention that the enantiomeric excess is conserved through the rearrangement and can even be improved by recrystallization. Under acidic conditions, trans,cis,cis-cyclobutane $\mathbf{7}$ was epimerized into trans,trans,trans-cyclobutane $\mathbf{8}$ and the carboxylic functions were converted into methyl esters. The temporary protection of the ketones as acetals allowed the formation of diazide $\mathbf{9}$. The reduction of the azide functions was necessary to install the amide side chains using reagent $\mathbf{1 0}$. The guanidinium parts were prepared by $\alpha$-chlorination of the ketones, before displacement with sodium diformylamide, hydrolysis of the imides, and treatment with cyanamide.

The overall yield was excellent with $24 \%$ over 18 steps from dimethyl acetylenedicarboxylate. Additionally the Baran group found a pathway to transform sceptrin into ageliferin. ${ }^{18}$

The hidden symmetry of the target molecule was brilliantly exploited in the synthetic plan by taking advantage of the epimerization of $\mathbf{7}$ and the rearrangement of the intermediate oxaquadricyclane $\mathbf{5}$. The central carbon skeleton of the target molecule is already included in cycloadduct $\mathbf{1}$. Only five steps were necessary to obtain the cyclobutane ring with the substituents in the correct configurations from the desymmetrized molecule $\mathbf{2}$. Indeed, the final steps only consisted of post-functionalizations of the side chains.

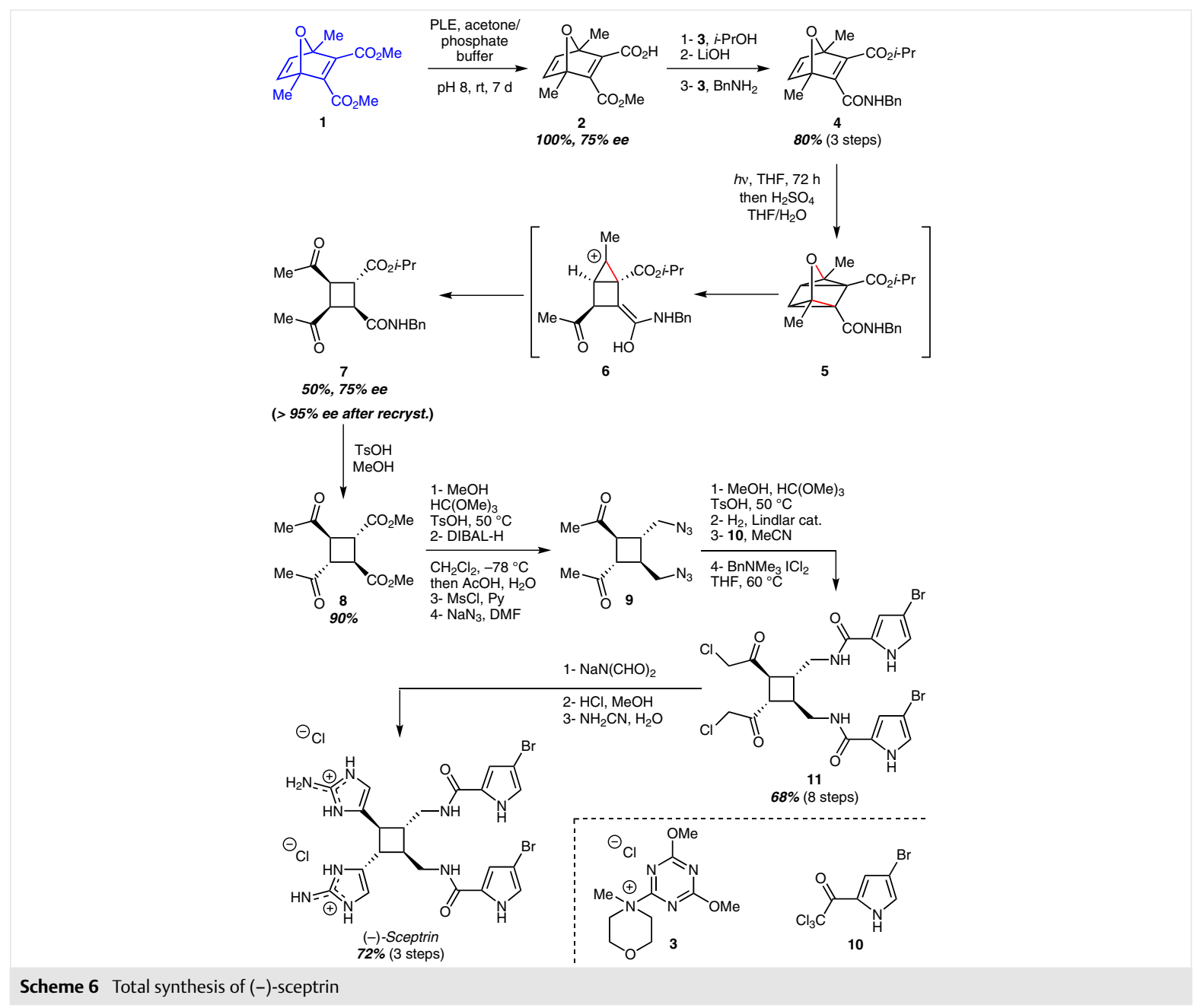




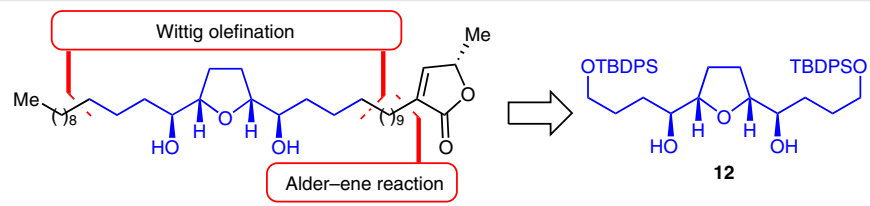

Scheme 7 Stark's retrosynthetic plan of cis-solamin

\section{2 cis-Solamin (Stark, 2006)}

cis-Solamin belongs to the Annonaceous acetogenins, a class of natural products isolated from the tropical plant Annonacea. ${ }^{19}$ Due to the range of biological activities (antitumor, immuno-suppressor, etc.), the synthesis of several acetogenins have been conducted. ${ }^{20}$ In 2006, Göksel and Stark described the synthesis of cis-solamin, an acetogenin bearing a polyhydroxylated cis-tetrahydrofuran and a butenolide moiety. ${ }^{21}$ Due to the apparent symmetry of the tetrahydrofuran diol central part, the authors proposed a synthetic sequence involving meso-diol 12 (Scheme 7).

The preparation of meso-diol 12 relies on a methodology developed in the Stark group and based on the highly diastereoselective oxidative cyclization of 1,5 -dienes. ${ }^{22}$ The synthetic sequence begins with a selective monodihydroxylation of $(E, E, E)$-cyclododeca-1,5,9-triene (13) followed by its oxidative cleavage promoted by sodium periodate (Scheme 8). The corresponding aldehydes were reduced to alcohols with sodium borohydride and then protected as silyl ethers. The resulting $(E, E)$-1,5-diene $\mathbf{1 4}$ was transformed into dihydroxylated tetrahydrofuran 12 with complete diastereoselection.

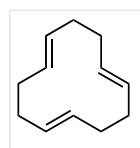

13

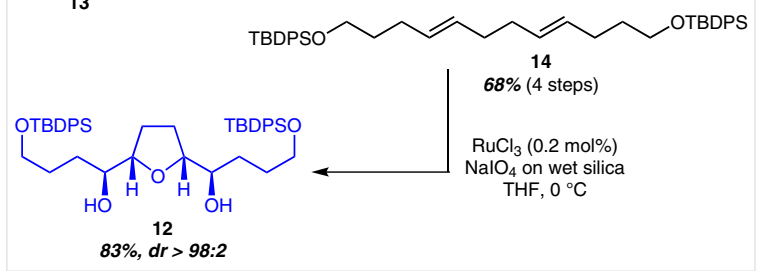

Scheme 8 Synthesis of meso-diol 12

Stark adopted an indirect strategy desymmetrizing the secondary alcohols to discriminate the endpoints of the side chains. Indeed, the enantioselective desymmetrization of meso-diol 12 was efficiently performed through transesterification using lipase Amano AK as a biocatalyst (Scheme 9). After desilylation, triol $\mathbf{1 5}$ was oxidized using a catalytic amount of tetrapropylammonium perruthenate leading to the formation of a $\gamma$-lactone moiety on the right side and an aldehyde function on the left side of the molecule. A Wittig olefination was performed in situ with the ylide formed from the reaction between KHMDS and phosphonium salt 16 to afford bicyclic compound 17. The use of DIBAL-H allowed the removal of the acetate group and the conversion of the lactone moiety into a lactol, which was involved, also in situ, in a second Wittig reaction with the ylide preformed from $n$-BuLi and phosphonium salt 18. cis-Solamin was achieved by the construction of the butenolide moiety involving a ruthenium-catalyzed Alder-ene reaction between triene 19 and propargylic alcohol 20 described by Trost ${ }^{23}$ and followed by chemoselective reduction with diimide.

The rapid preparation of the meso precursor together with the efficient distinction between the terminal hydroxyl functions, via a relay of the desymmetrization from the secondary alcohols, led to an efficient synthesis of this natural product.

\subsection{Crocacin C (2010, Bressy/Pons)}

Crocacin $\mathrm{C}$ is one of the four members of the crocacin subfamily. It was isolated in 1994 by Janssen and co-workers from the myxobacterium Chondromyces crocactus and exhibits moderate antibacterial activity, accompanied by antifungal and cytotoxic properties. ${ }^{24}$ This polyketide congener containing a $(E, E)$-dienamide and $(E)$-styryl moiety displays a stereotetrad anti-anti-syn. Several syntheses of this natural product ${ }^{25}$ have been developed that mainly using starting material from the chiral pool or stoichiometric chiral reagents to install new stereogenic centers. In 2009, we described an enzymatic desymmetrization of meso intermediates leading to tetrahydropyran building blocks bearing up to five stereogenic centers. ${ }^{26}$ To illustrate its synthetic value, we applied it to the total synthesis of crocacin C. The detection of a hidden symmetric guided our retrosynthetic analysis toward the use of meso-diol 21 through a convergent strategy (Scheme 10). ${ }^{27}$

The scalable and diastereoselective synthesis of meso compound $\mathbf{2 1}$ was accomplished in three steps from the easily available oxabicyclic compound $\mathbf{2 2}$ (Scheme 11). ${ }^{28}$

The desymmetrization of meso intermediate $\mathbf{2 1}$ was catalyzed by Rhizomucor miehei leading to monoester $\mathbf{2 4}$ in $87 \%$ yield and $>99: 1$ er (Scheme 12 ). Then, a sequence of Swern oxidation/Julia modified olefination with sulfone $\mathbf{2 5}$ allowed installation of the styryl moiety. After saponification and chlorination of the corresponding alcohol, (chloro- 

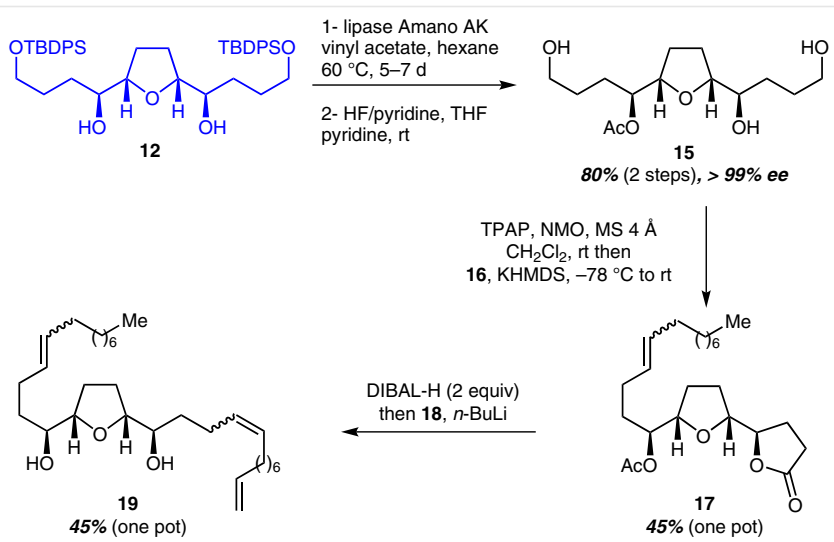

$\mathrm{CH}_{2} \mathrm{Cl}_{2}$, it then

$\mathrm{CH}_{2} \mathrm{Cl}_{2}$, it then
16, $\mathrm{KHMDS},-78^{\circ} \mathrm{C}$ to rt
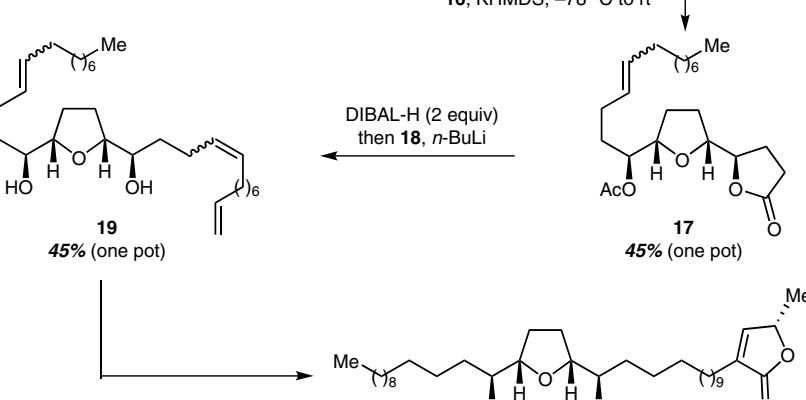

DIBAL-H (2 equiv) then $18, n$-BuLi

$45 \%$ (one pot)

1- $\mathrm{CpRu}(\mathrm{MeCN})_{3} \mathrm{PF}_{6}$ (cat.)

Me

Me

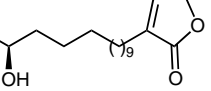

cis-Solamin
$\mathbf{8 1 \%}$ (2 steps)

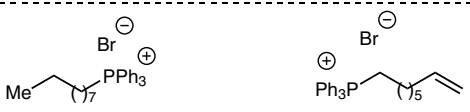

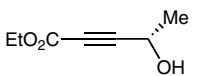

20

Scheme 9 Desymmetrization of meso-diol 12 and completion of the synthesis

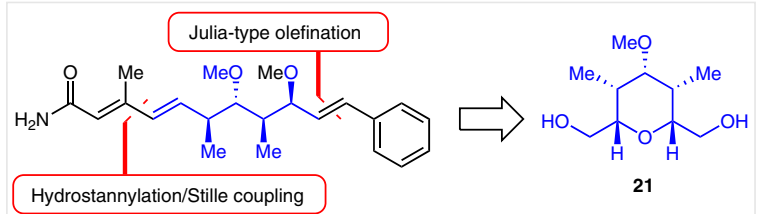

Scheme 10 Bressy/Pons' Retrosynthetic analysis of crocacin C

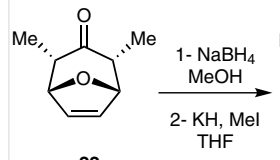

Scheme 11 Preparation of meso-diol 21

methyl)tetrahydropyran $\mathbf{2 7}$ was subjected to excess LDA thereby opening the cyclic ether and revealing the stereotetrad terminated by an alkyne function; subsequent methylation afforded diether $\mathbf{2 8}$. The synthesis was completed with a one-pot hydrostannylation/Stille coupling with iodoenamide $\mathbf{2 9}$ using the same source of palladium.
In this synthesis, the four stereogenic centers of the target were enantioselectively controlled in a single step. Additionally, no protecting group was required. ${ }^{29}$ Only eleven steps were needed to obtain, with an excellent $22 \%$ overall yield, the natural product from oxabicyclic compound $\mathbf{2 2}$.

\section{Metallocatalyzed Desymmetrization}

The variety of the enantioselective metallocatalyzed transformations offers multiple possibilities to promote desymmetrization. Schreiber was probably one of the first to involve enantioselective metal-catalyzed reactions in strategies based on the detection of hidden symmetry. ${ }^{30}$ His group employed mainly Katsuki-Sharpless epoxidation to prepare polyketide natural products.

\subsection{Quadrigemine C (2002, Overman)}

In 2002, Overman's group reported a straightforward total synthesis of quadrigemine $\mathrm{C}$, a higher-order member of the pyrrolidinoindoline alkaloids. ${ }^{31}$ This natural product was described in 1987 in New Caledonia from Psychotria oleoides, a plant used for pain treatment. ${ }^{32}$ As a key step of the synthesis, Overman proposed to desymmetrize a highly elaborated meso precursor $\mathbf{3 0}$ due to the local symmetry in 


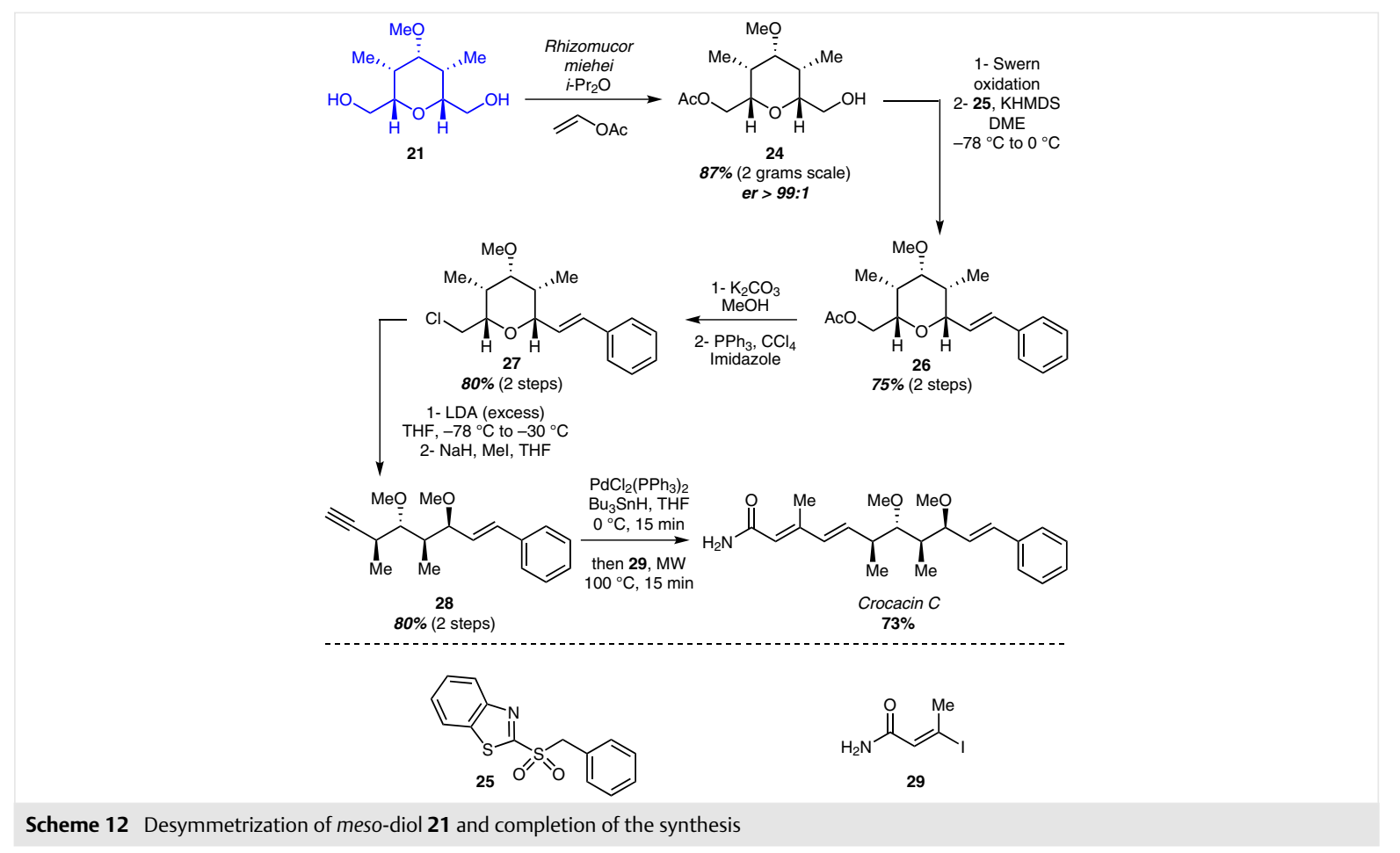

the central part of the target alkaloid (Scheme 13). The strategy was based on a late double intramolecular enantioselective Heck reaction.

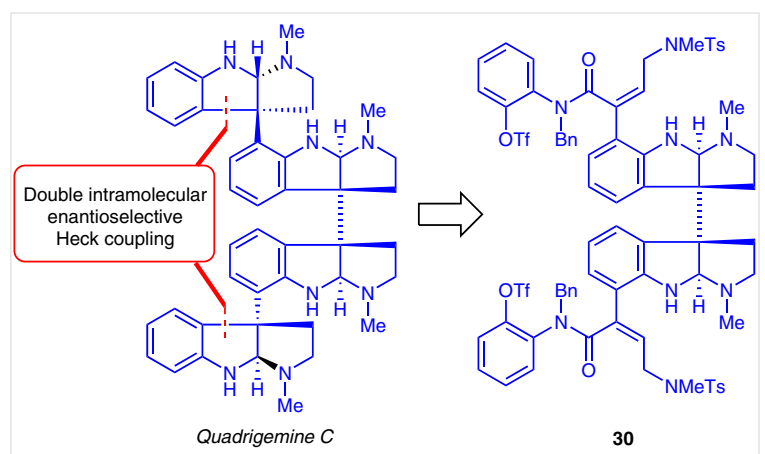

Scheme 13 Overman's retrosynthetic analysis of quadrigemine $C$

The synthesis started from a symmetric natural product, meso-chimonanthine $\mathbf{3 1}$, previously prepared by the same group from oxindole and isatin in 13 steps and 35\% overall yield (Scheme 14). ${ }^{33}$ The sequence is typical of a bidirectional approach with a symmetrical double reactivity for each step of the synthesis. ${ }^{34}$ First of all, Boc protection was installed on the free aminal functions of meso-chimonanthine $\mathbf{3 1}$ in order to guide the orthometalation step. The double lithiation was followed by iodination before the removal of the carbamate groups. Diiodo intermediate $\mathbf{3 4}$ was then coupled with stannane $\mathbf{3 5}$ in a palladium-catalyzed Stille reaction to form meso precursor 30, which was desymmetrized in the key step using a catalytic amount of a chiral palladium complex. Indeed it serves to promote an enantioselective double intramolecular Heck coupling, which introduced two new quaternary stereocenters during the transformation. This strategy involved a methodology previously developed by Overman's group. ${ }^{35}$ It is noteworthy to mention that in addition to the desired product 36, obtained with good enantioselectivity, significant amounts of meso stereoisomers $(14 \%+7 \%)$ were also produced during this key step, thus highlighting a strong Horeau amplification. The catalytic hydrogenation of the double bond followed by the use of sodium in ammonia provided quadrigemine $\mathrm{C}$, which is also a precursor of psycholeine obtained through rearrangement under acidic conditions.

The bidirectional strategy, adopted in this total synthesis, allowed the rapid preparation of an advanced meso precursor, demonstrating the power of the enantioselective catalytic desymmetrization of meso compounds. 

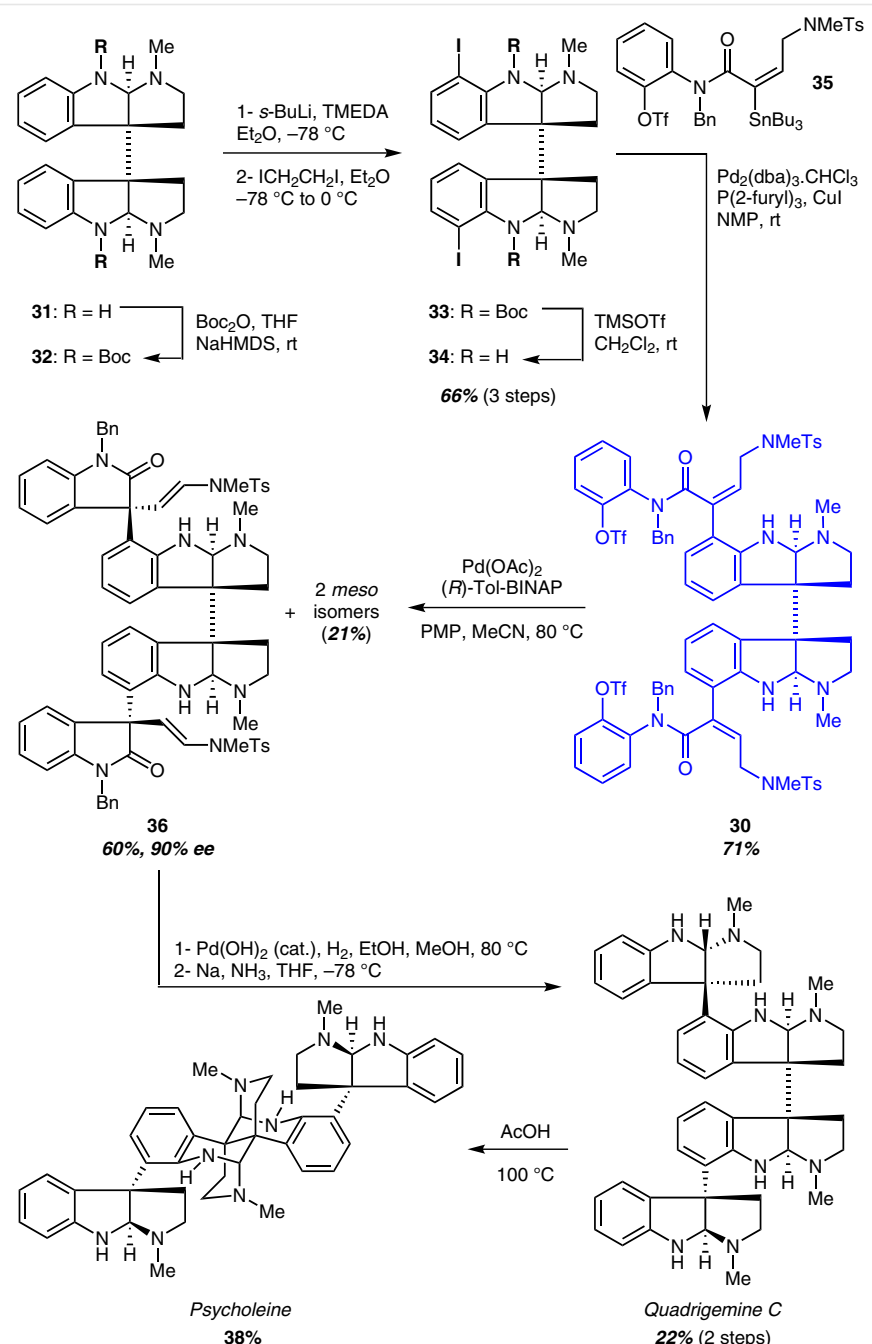

Scheme 14 Synthesis of quadrigemine C from meso-chimonanthine

\section{2 (+)-Homochelidonine (2007, Lautens)}

In 2007, Lautens' group described the first enantioselective total synthesis of (+)-homochelidonine, ${ }^{36}$ an alkaloid isolated, in 1839, from the roots of Chelidonium majus. ${ }^{37}$ This group adopted a convergent strategy based on a palladium-catalyzed enantioselective ring opening of the mesoazabicycle $\mathbf{3 7}$ using an elaborated boronic acid (Scheme 15).

The meso intermediate was prepared in four steps, from dibromoveratrole $\mathbf{3 8}$, through the generation of a benzyne intermediate, acting as a dienophile in a Diels-Alder reaction with a protected pyrrole (Scheme 16).

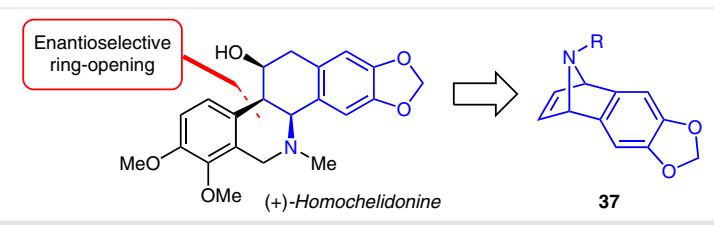

Scheme 15 Lautens' retrosynthetic analysis of (+)-homochelidonine

After optimization, it was found that $(S)$-Tol-BINAP was the most selective ligand to promote the coupling between meso-azabicycle 37a (or 37b) and boronic acid $\mathbf{4 1}$ affording product 42a (or $\mathbf{4 2 b}$ ) under mild conditions (Scheme 17). Here two out of three stereogenic centers were installed through the enantioselective desymmetrization step. 


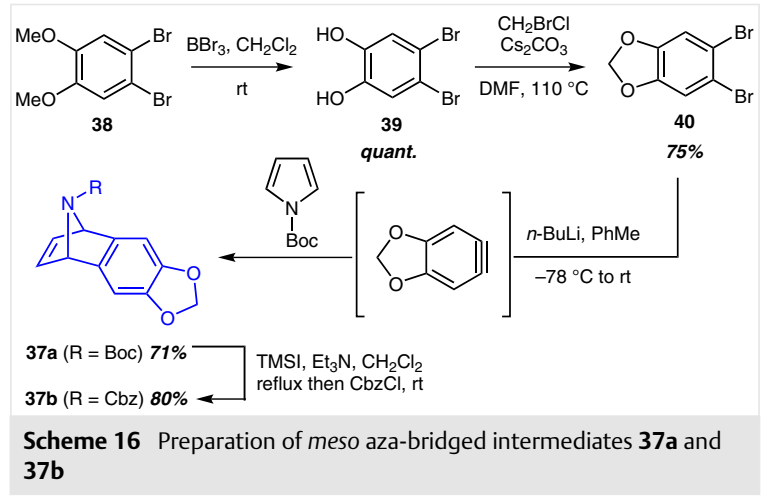

OMe ОМOM

41 (1.5 equiv) $\quad \mathrm{Pd}(\mathrm{MeCN})_{2} \mathrm{Cl}_{2}(5 \mathrm{~mol} \%)$

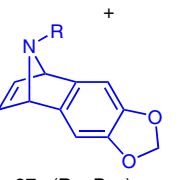

$37 \mathrm{a}(\mathrm{R}=\mathrm{Boc})$ or

37b $(\mathrm{R}=\mathrm{Cbz})$

Scheme 17 Pd-catalyzed enantioselective ring opening of the meso intermediates $\mathbf{3 7} \mathbf{a}$ and $\mathbf{3 7} \mathbf{b}$

The nitrogen-containing heterocyclic compound $\mathbf{4 3}$ was then formed after deprotection of the methoxymethyl group in 42b under acidic conditions and bromination of the corresponding alcohol using Appel's conditions (Scheme 18). The third stereogenic center was introduced diastereoselectively using an olefin epoxidation on the most hindered face of the molecule. This epoxidation required a two-step sequence, first a regio- and stereoselective formation of bromohydrin $\mathbf{4 4}$ followed by the ring-closure step under basic conditions. Lastly, the corresponding epoxide $\mathbf{4 5}$ was regioselectively opened using $\mathrm{LiAlH}_{4}$ to afford (+)-homochelidonine.

This enantioselective synthesis in only 11 steps from dibromoveratrole $\mathbf{3 8}$ appeared highly efficient in term of selectivities and overall yield (15\%).

\section{3 (-)-Cyanthiwigin $F(2008$, Stoltz)}

In 2008, Enquist and Stoltz disclosed an extremely efficient and elegant total synthesis of (-)-cyanthiwigin $\mathrm{F}^{38}$ a member of the cyathane family, isolated from the marine sponge Myrmekioderma styx. The natural product exhibits interesting biological activity, such as cytotoxicity against human tumor cells. (-)-Cyanthiwigin F presents a tricyclic structure with two quaternary stereogenic centers at the

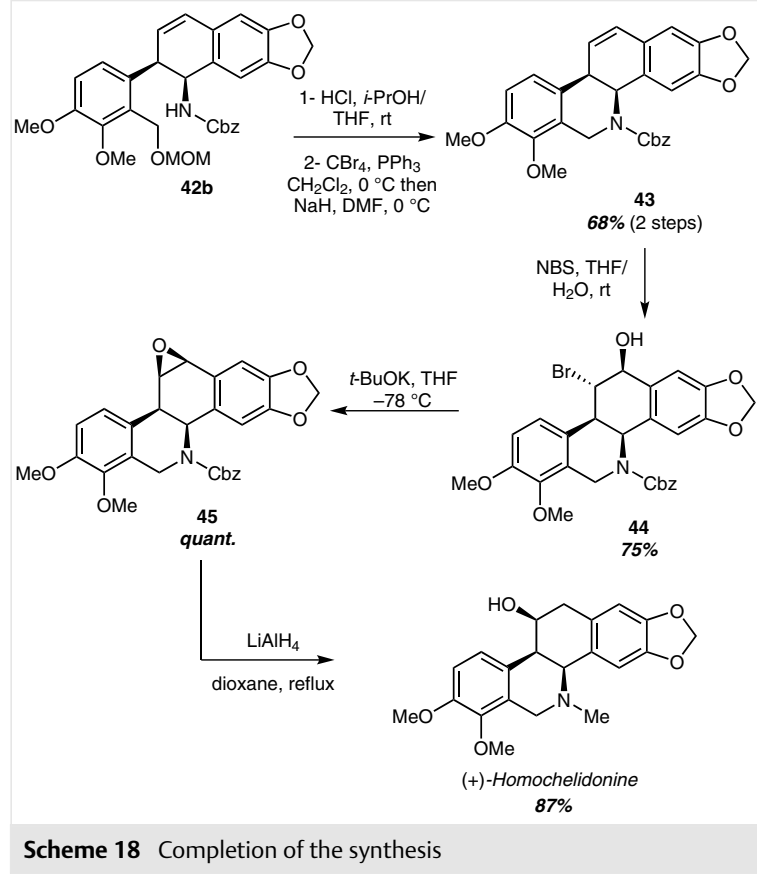

ring junctions. The Stoltz group planned to build the fiveand seven-membered rings after ensuring the stereocontrol of the quaternary stereocenters around the central sixmembered ring. Unlike the other examples reviewed in this paper, the authors harnessed a scarcely employed centrosymmetric meso compound (Scheme 19). ${ }^{39}$

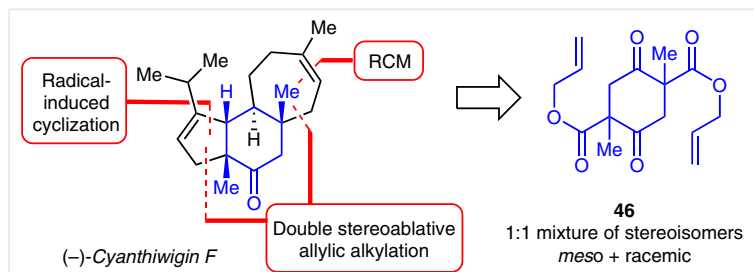

Scheme 19 Stoltz's retrosynthetic analysis of (-)-cyanthiwigin F

Diallyl succinate (47) was self-condensed through a Claisen-Dieckmann process. This reaction was followed by a double alkylation, promoted under basic conditions leading to a 1:1 diastereomeric mixture of diketo diester $\mathbf{4 6}$ (Scheme 20).

From the mixture of meso and racemic diketo ester 46 a stereoconvergent enantioselective palladium-catalyzed allylic alkylation was performed leading to enantiopure $C_{2}-$ symmetric diketone $(R, R)-\mathbf{4 8}$ accompanied by its diastereomer meso diketone meso-48 (Scheme 21). A double stereoablative process ${ }^{40}$ takes place through the generation of 

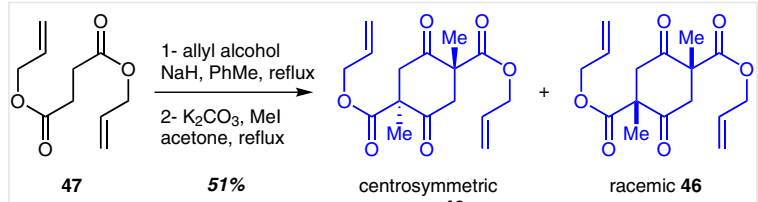

meso 4

1:1 mixture of stereoisomers meso + racemic

Scheme 20 Preparation of key intermediate $\mathbf{4 6}$

intermediate enolates by decarboxylation. ${ }^{41}$ The power of the Horeau amplification through two successive stereoselective reactions is perfectly illustrated in this case.

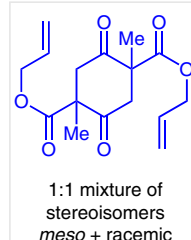

46

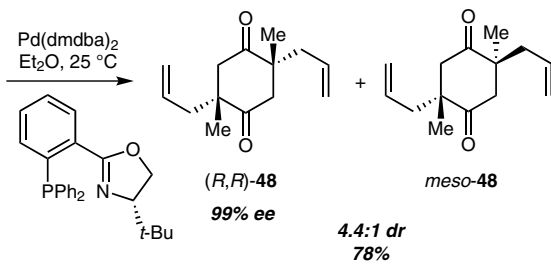

$78 \%$
Scheme 21 Palladium-catalyzed double stereoablative enantioselective allylic alkylation

One of the two ketone functions of $C_{2}$-symmetric compound $(R, R)-\mathbf{4 8}$ was then converted into a vinyl triflate and used as partner in a Negishi cross-coupling with an homoallylzinc partner (Scheme 22). In the presence of metathesis catalyst $\mathbf{5 0}$ and the vinylboronic pinacol ester, triene 49 underwent a ring-closure-metathesis leading to

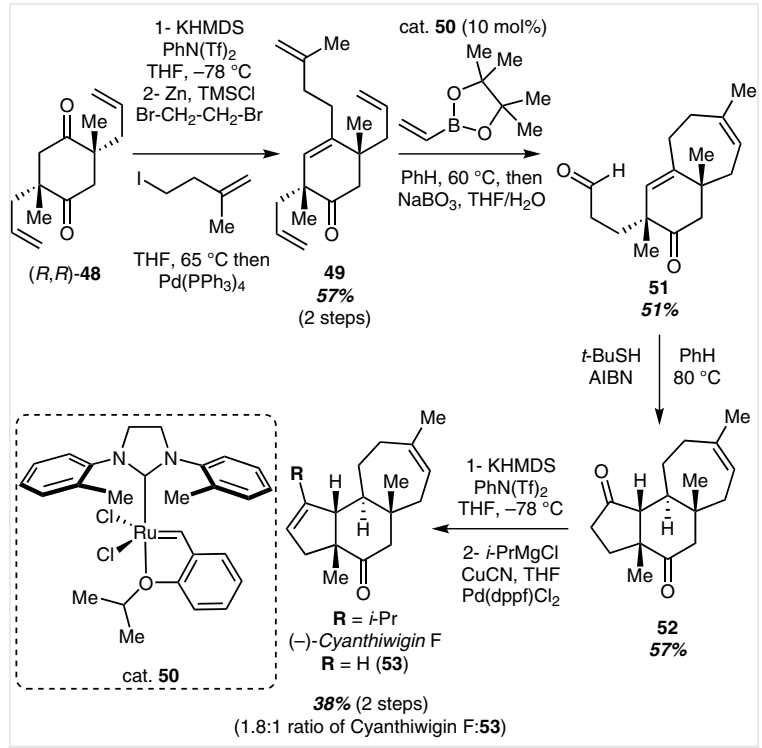

Scheme 22 Completion of the total synthesis the formation of a seven-membered ring and also a crossmetathesis functionalizing the other pendant allyl group. ${ }^{42}$ Subsequent oxidation converted the vinylboronate into an aldehyde. Ketoaldehyde $\mathbf{5 1}$ was cyclized through a radical process to obtain diketone $\mathbf{5 2}$. A chemoselective deprotonation of the newly formed ketone function allowed the formation of a novel vinyl triflate, which underwent subsequent cross-coupling with isopropylcuprate. A mixture of the desired natural product and the reduced vinyl triflate 53 was then obtained.

In 2016 the same group improved the synthetic pathway, using an anti-Markovnikov Wacker oxidation, to obtain ketoaldehyde $\mathbf{5 1}$ in better yield. ${ }^{43}$

In this total synthesis, the double stereoablative decarboxylative allylation provided a chiral building block with high enantiopurity illustrating the power of the amplified process. This example presents also one of the rare use of a centrosymmetric meso compound in total synthesis.

\section{4 [5]-Ladderanoic Acid (2016, Gonzalez- Martinez/Boxer/Burns)}

Recently, the synthesis of [5]-ladderanoic acid was achieved thanks to the conjoint efforts of the groups of Gonzalez-Martinez, Boxer, and Burns during the total synthesis of a more complex ladderane phospholipid. ${ }^{44}$ This natural product presents an uncommon pentacyclobutane framework. [5]-Ladderanoic acid was only previously synthesized by Mascitti and Corey in racemic and enantioselective fashions. ${ }^{45}$ The authors elaborated a retrosynthetic plan involving a late desymmetrization of polycyclic cyclobutene 54, and a Zweifel cross-coupling to introduce the side chain (Scheme 23).

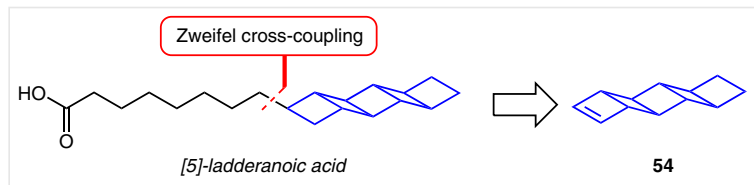

Scheme 23 Retrosynthetic analysis of [5]-ladderanoic acid

meso-Cyclobutene $\mathbf{5 4}$ was prepared in seven steps starting from commercially available meso-cyclobutanediol $\mathbf{5 5}$ (Scheme 24). Its double mesylation preceding double displacement by a sulfur atom source afforded a bicyclic tetrahydrothiophene, which was successively oxidized to give the sulfoxide and then chlorinated in the $\alpha$-position to the sulfur atom. The corresponding sulfoxide $\mathbf{5 6}$ was subjected to basic conditions, leading to cyclobutene $\mathbf{5 7}$ after a Ramberg-Bäcklung olefination. This bicyclic cyclobutene was then dimerized under photochemical conditions in the presence of copper triflate. Pentacyclic product $\mathbf{5 8}$ was then the substrate of a tetramesitylporphyrinatomanganese(III) complex [Mn(TMP)Cl] catalyzed $\mathrm{C}-\mathrm{H}$ chlorination according to a procedure described by Liu and Groves in $2010 .^{46}$ 

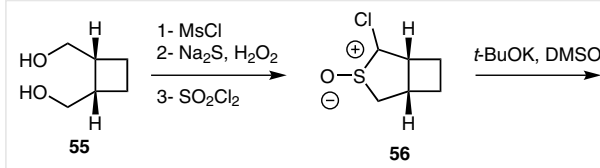

(3 steps)

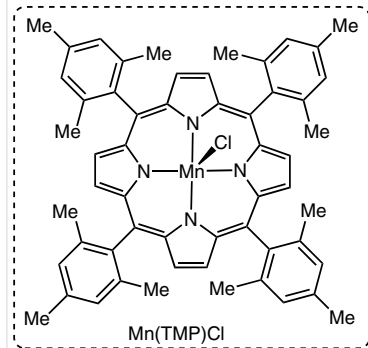

$\vdots$
$\vdots$
$\vdots$
$\vdots$
$\vdots$
$\vdots$

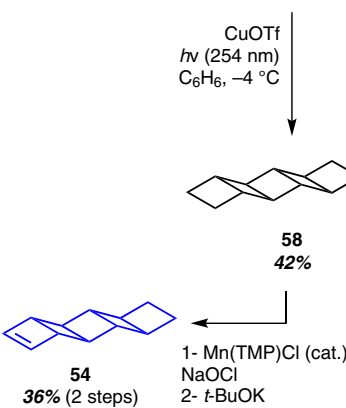

Scheme 24 Preparation of meso-pentacyclic cyclobutene 54

A subsequent elimination promoted by potassium tertbutoxide furnished the pentacyclic cyclobutene 54. Enantioselective hydroboration catalyzed by a chiral copper complex recently described by the group of Tortosa was employed to manage the desymmetrization key step (Scheme 25). ${ }^{47}$ Impressively, the desymmetrization of meso-cyclobutene 54 revealed eight stereogenic centers and created a new one. The corresponding pinacolboronate $\mathbf{5 9}$ was then subjected to Zweifel cross-coupling ${ }^{48}$ using a vinyllithium partner to introduce the side chain to obtain product $\mathbf{6 0}$. Three additional steps were required to obtain the natural product on a preparative scale.

Here the late desymmetrization allowed the formulation of a scalable route to [5]-ladderanoic acid, a compound convenient for further biological studies. All nine stereogenic centers of the final product were efficiently controlled during the key desymmetrization step.

\section{Organocatalyzed Desymmetrization}

Organocatalysis has emerged as the third pillar of enantioselective catalysis since its conceptualization at the early 2000s. Several new tools were developed since this renaissance displaying orthogonal modes of action compared to metallocatalysis. The combination of the hidden symmetry detection and organocatalytic processes ${ }^{5 b}$ has been fruitful and it has led to elegant total syntheses.

\section{1 (+)-Hirsutene (2008, List)}

In 2008, List's group applied an organocatalyzed transannular aldol reaction methodology to the total synthesis of (+)-hirsutene (Scheme 26). ${ }^{49}$ This sesquiterpene, isolated from Basidiomycete Coriolus consors, ${ }^{50}$ is a biosynthetic intermediate for other natural products with significant biological activities, such as hirsutic acid and coriolin. List proposed a straightforward synthetic plan ${ }^{51}$ involving the meso [6.3.0] bicyclic intermediate 61, desymmetrized through a transannular contraction of the eight-membered ring to afford the triquinane core.

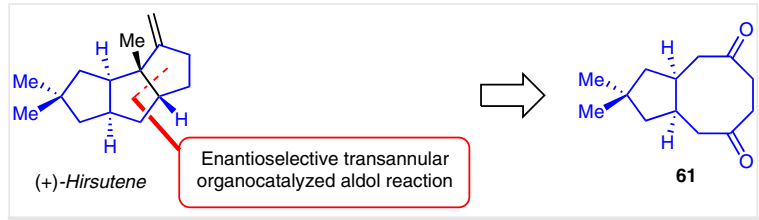

Scheme 26 List's retrosynthetic analysis of (+)-hirsutene

Bicyclic meso-1,4-dione $\mathbf{6 1}$ was synthesized in nine steps from commercially available 3,3-dimethylpentanedioic acid (Scheme 27). Diacid 62 was first converted into the double Michael acceptor 63 through a bidirectional elongation using a three-step sequence. Then a magnesium-mediated radical cyclization led to the cyclopentane 64 as a mixture of diastereomers. The ester functions of compound $\mathbf{6 4}$

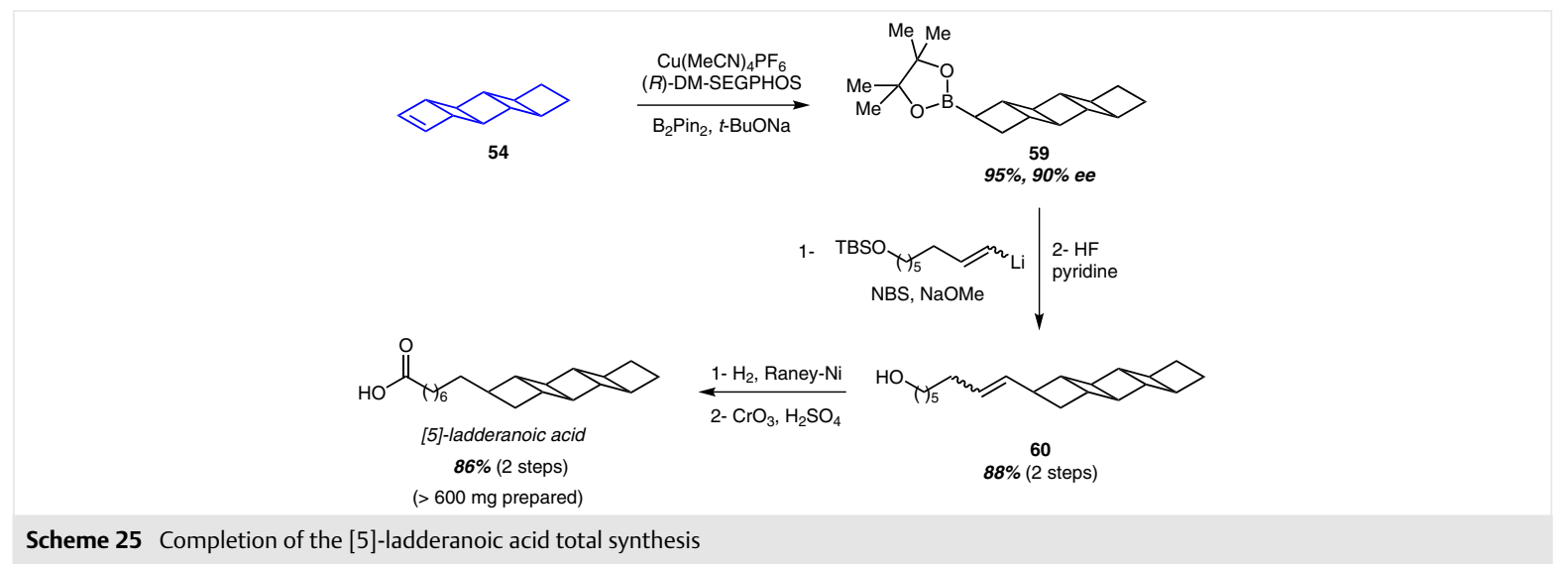


were both transformed into diazo ketones through a threestep sequence. Bisdiazo intermediate $\mathbf{6 5}$ cyclized when treated with catalyst $\mathbf{6 6}$, forming the cyclooctenedione $\mathbf{6 7}$ as a mixture of separable diastereomers. ${ }^{52} \mathrm{~A}$ final hydrogenation provided meso compound $\mathbf{6 1 .}$

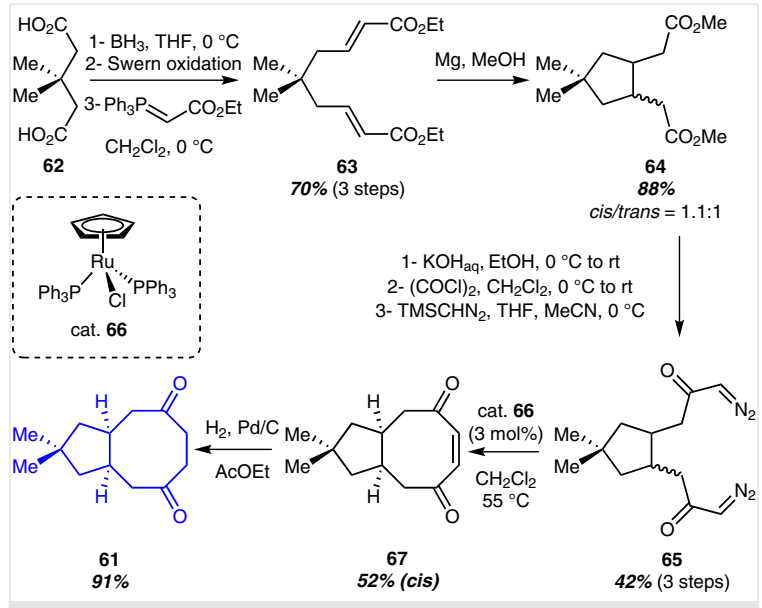

Scheme 27 Preparation of meso-diketone $\mathbf{6 1}$

The direct enantioselective transannular aldol reaction was performed using trans-4-fluoroproline (68) under mild conditions to furnish tricyclic hydroxy ketone $\mathbf{6 9}$ as a single diastereomer in excellent yield and enantioselectivity (Scheme 28). List and co-workers proposed the well-organized transition state depicted in the Scheme 28 below to explain the observed stereoselectivity.

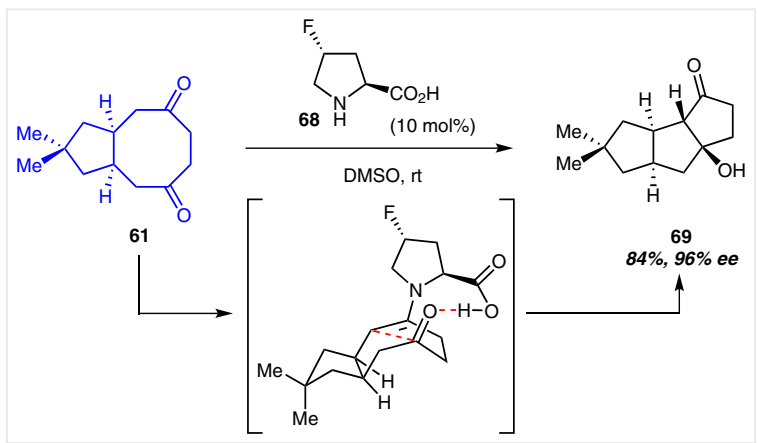

Scheme 28 Enantioselective organocatalyzed desymmetrization of meso-diketone 61 through transannular aldol reaction

Three additional steps were required to obtain (+)-hirsutene (Scheme 29). First a base-promoted elimination gave enone $\mathbf{7 0}$ in quantitative yield without affecting the enantiomeric ratio, which might be possible through a retro-aldol/aldol process. In presence of lithium in ammo- nia, enone $\mathbf{7 0}$ was reduced to form an enolate, which was trapped with methyl iodide to give ketone $\mathbf{7 1}$. Ultimately, Wittig olefination provided the natural product.

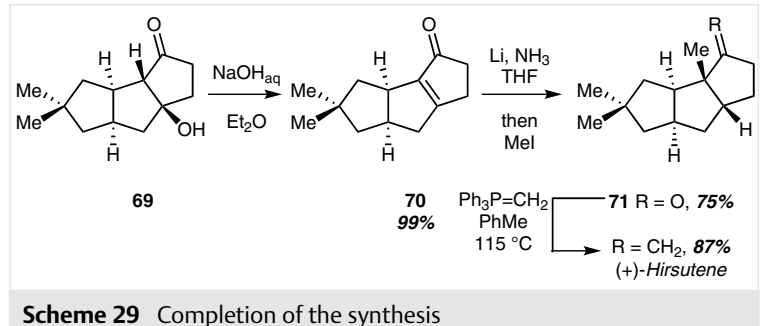

This remarkable synthesis, which involves a late organocatalyzed desymmetrization, required only twelve steps. The transannular aldolization was highly efficient in term of yield and enantioselectivity.

\subsection{Alstoscholarines (2011, Neuville/Zhu)}

Both (E)- and (Z)-alstoscholarines, two monoterpenoid indole alkaloids, were isolated from leaves of Alstonia scholaris, a plant used in asian traditional medicine..$^{53}$ These two alkaloids present an unusual pentacyclic structure bearing an indole and a pyrrole moieties connected by a central [3.3.1] bicyclic framework. In 2011, Gerfaud, Neuville, and Zhu described the first straightforward enantioselective total synthesis of these two diastereomeric natural products. ${ }^{54}$ Their strategy involved the desymmetrization of meso cyclic anhydride 72 (Scheme 30) and featured also two other pivotal steps, which are the indole synthesis and a Pictet-Spengler cyclization.

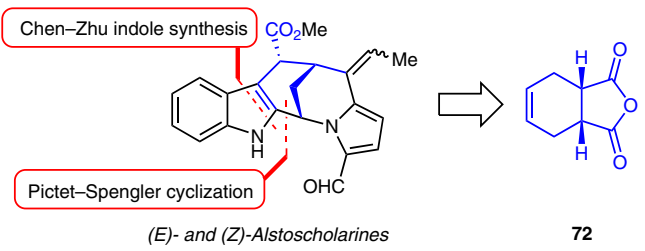

Scheme 30 Retrosynthetic analysis of alstoscholarines

The synthetic sequence started with the organocatalyzed enantioselective desymmetrization of meso-anhydride $\mathbf{7 2}$ triggered by Song's catalyst $\mathbf{7 3}$ under mild conditions, to give monoester $\mathbf{7 4}$ in excellent yield and enantioselectivity (Scheme 31). ${ }^{55}$ This last intermediate was converted into pyrroloketone $\mathbf{7 6}$ through the transitory formation of a thioester according to a Nicolaou's procedure. ${ }^{56}$ The double bond underwent an oxidative cleavage leading to the formation of hemiaminal $\mathbf{7 7}$. Using the palladiumcatalyzed Chen-Zhu indole synthesis, ${ }^{57}$ aldehyde $\mathbf{7 7}$ in the presence of $o$-iodoaniline (78) is converted into compound 


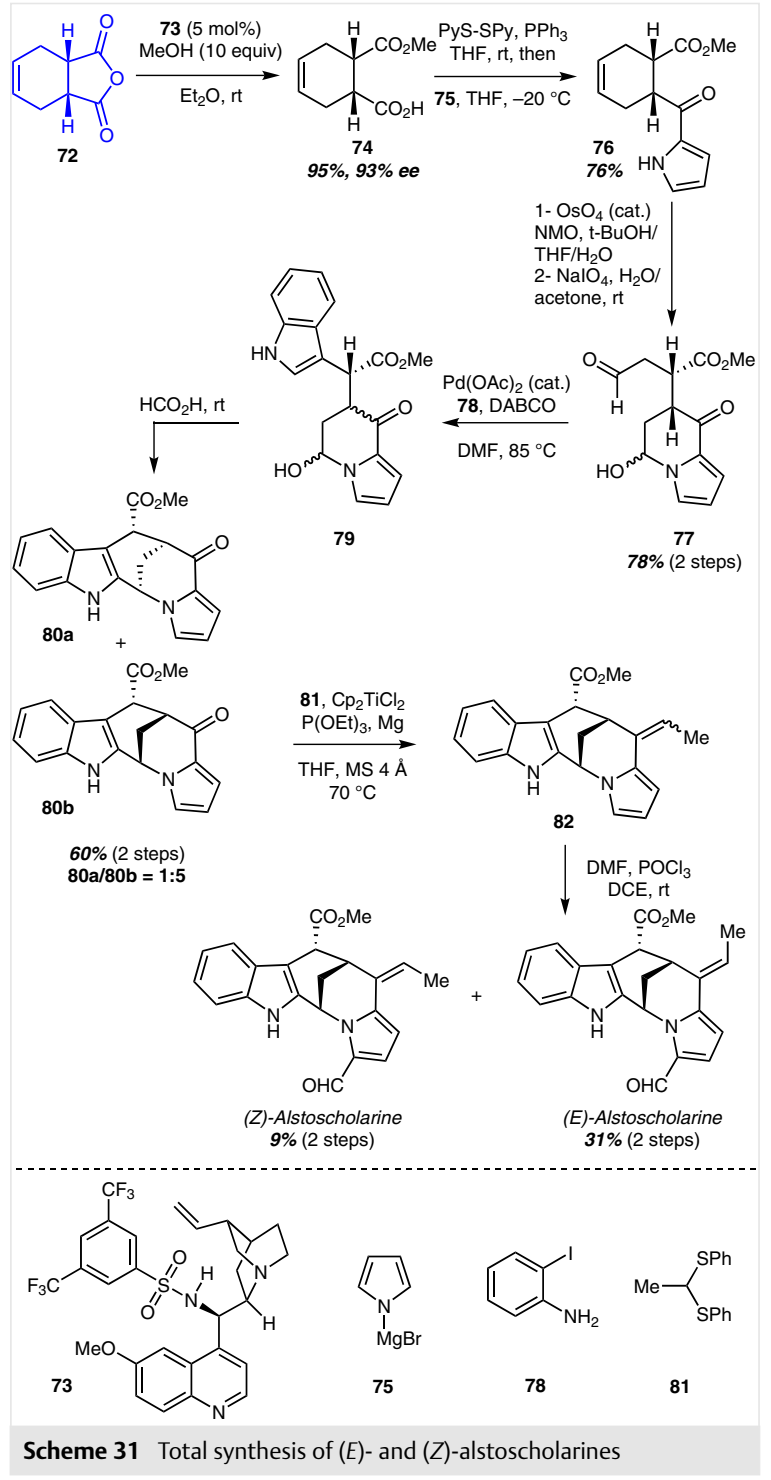

79 with a partial epimerization of the $\alpha$-position of the ketone. To limit this deleterious problem, a shorter reaction time (40 min) was required. It is noteworthy that the Fischer indole synthesis was not applicable due to the degradation of aldehyde $\mathbf{7 7}$ under acidic conditions. Hemiaminal 79, in the presence of formic acid, cyclized via a Pictet-Spengler reaction allowing the installation of the central bicyclic core. The resulting major isomer $\mathbf{8 0 b}$ was then transformed through two steps into the natural products. First a titanium-mediated olefination was performed using dithioacetal 81, according to Takeda's procedure. ${ }^{58}$ The reaction gave the instable intermediate $\mathbf{8 2}$ as a mixture of diastereomers, which was directly submitted to Vilsmeier-Haack formylation to afford the two natural products in a 3:1 E/Z diastereomeric ratio.

This elegant protecting-group-free total synthesis ${ }^{29}$ required only eight steps and gave a $14 \%$ overall yield. Its efficiency is related to the straightforward strategy adopted by the authors, which included the detection of hidden symmetry. Unlike many previous examples, the enantioselective desymmetrizing step occurred very early in the synthetic sequence.

\section{3 (-)-Diospongin A (2015, Chuzel/Bressy)}

Diospongin A belongs to the diarylheptanoid natural products family and presents anti-osteoporotic activities. ${ }^{59}$ Despite the numerous reported syntheses of this natural product, ${ }^{60}$ its hidden symmetry remained unexploited. ${ }^{10}$ Indeed, a new synthetic plan was imagined based on the key meso intermediate $\mathbf{8 3}$ (Scheme 32).

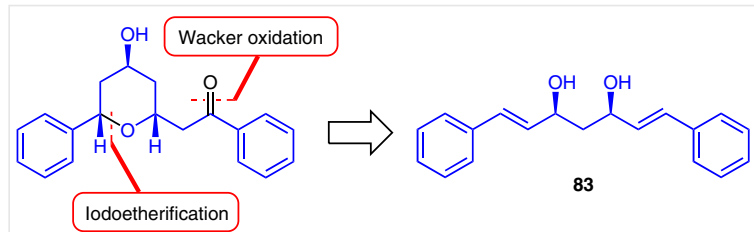

Scheme 32 Chuzel/Bressy's retrosynthetic analysis of (-)-diospongin A

To achieve this goal, an associated methodology was developed to desymmetrize acyclic meso-1,3-diols, which appeared rather difficult due to the high number of possible conformations. An organocatalyzed acyl transfer was envisioned to break the symmetry of diol $\mathbf{8 3}$, easily synthesized in scalable amounts in two steps (aldol reaction and then syn-reduction of the ketone). Chiral isothioureas ${ }^{61}$ were found to be efficient catalyst to promote such challenging desymmetrization. The high level of enantioselectivity observed could be explained by the synergy between the desymmetrization step of diol $\mathbf{8 3}$ and the chiroablative kinetic resolution step of monoester $\mathbf{8 4}$ involved in the second acylation (Scheme 33). The global transformation leads to an improvement of the enantioselectivity of the reaction by forming a reusable byproduct $\mathbf{8 5}$. This subtractive Horeautype amplification has been observed only a few times in organocatalyzed enantioselective acyl transfer ${ }^{62}$ It should also be noted that this enantioselective acylation is extremely efficient as only $0.5 \mathrm{~mol} \%$ of the catalyst was necessary to achieve good yield and excellent ee in very short reaction time $(2.5 \mathrm{~h})$ at $-20^{\circ} \mathrm{C}$, which is rather uncommon in the field of organocatalysis. 


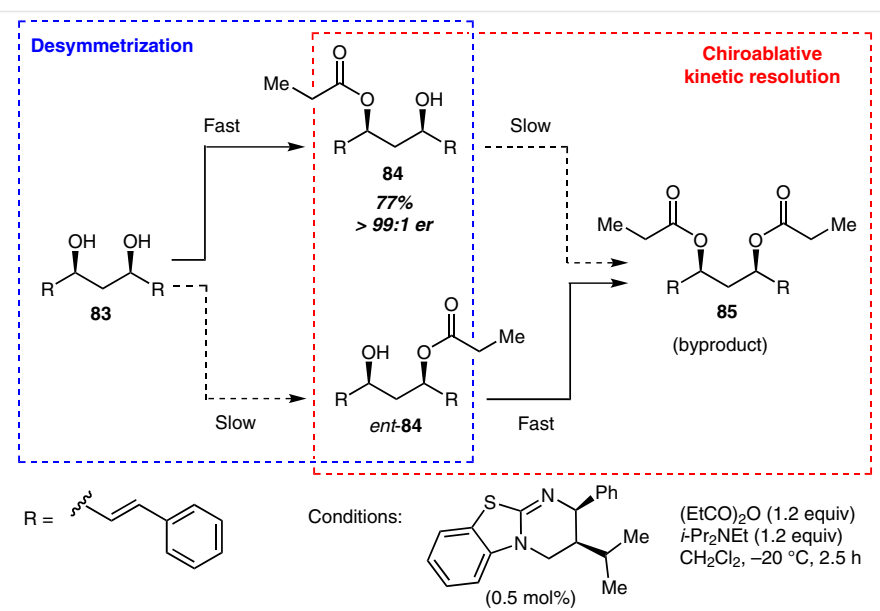

Scheme 33 Subtractive Horeau-type amplification during the organocatalyzed desymmetrization of meso-1,3-diol 83

From the desymmetrized hydroxyl ester 84, only few steps were necessary to obtain the natural product (Scheme 34). First an iodocycloetherification was performed under mild conditions to obtain compound $\mathbf{8 6}$ bearing a tetrahydropyran ring in high diastereoselectivity and yield without alteration of the enantiopurity. It is noteworthy that no racemization by intramolecular acyl transfer was observed during this crucial step. Then a radical deiodination was conducted on intermediate $\mathbf{8 6}$ before the hydrolysis of the ester function and a regioselective Wacker oxidation of the styryl moiety led to the target molecule.

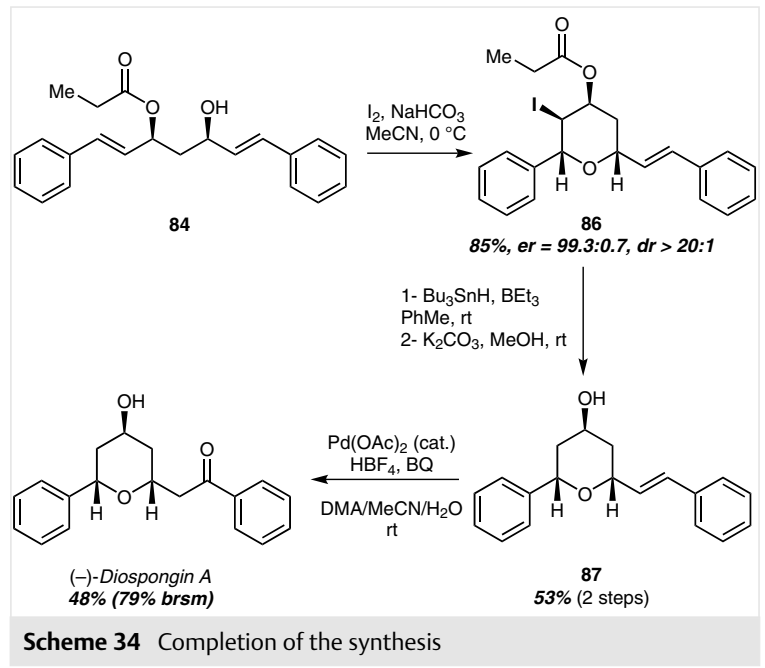

This synthesis required only one catalytic enantioselective step to control the absolute configuration of the natural product while previous syntheses employed several stoi- chiometric chiral reagents. Additionally this protecting group free synthetic sequence constitutes one of the shortest total syntheses of diospongin A with only seven steps. ${ }^{29}$

\section{Conclusion}

Meso compounds hold a particular status in stereoselective synthesis due to their achirality despite the presence of stereogenic elements. Their catalytic enantioselective desymmetrization appears as a powerful tool to rapidly provide complex building blocks bearing several stereogenic centers. Applied to the total synthesis of natural products, this approach allows the control of stereogenic centers with a notably reduced amount of chiral agents or catalysts. As a consequence, a new type of economy emerged from the junction between the hidden symmetry detection strategy and the catalytic enantioselective desymmetrization of meso molecules: the economy of chiral reagents/catalysts. We hope that the different examples of total synthesis highlighted in this review clearly illustrated this new attractive concept and highlighted the efficiency of this strategy.

\section{Acknowledgment}

The author thank Aix-Marseille Université, The Centre National de la Recherche Scientifique (CNRS) and the French Research Ministry (grant to J.M.). C.B. acknowledges the Agence Nationale de la Recherche (ANR) for grant ANR-10-JCJC-0710 (Orcademe Project). The authors warmly thank Dr Xavier Bugaut (Aix-Marseille Université) for proof reading. 


\section{References}

(1) Current address: University of Vienna, Department of Organic Chemistry, Währinger Strasse 38, 1090 Vienna, Austria.

(2) Pérec, G. La cloture et autres poèmes; Hachette/Collection P.O.L: Paris, 1980

(3) Ceulemans, A. J. Group Theory Applied to Chemistry; Springer: Dordrecht, 2013.

(4) Moss, G. P. Pure Appl. Chem. 1996, 68, 2193.

(5) For reviews, see: (a) Zeng, X.-P.; Cao, Z.-Y.; Wang, Y. H.; Zhou, F.; Zhou, J. Chem. Rev. 2016, 116, 7330. (b) Borissov, A.; Davies, T. Q.; Ellis, S. R.; Fleming, T. A.; Richardson, M. S. W.; Dixon, D. J. Chem. Soc. Rev. 2016, 45, 5474. (c) Wang, M.; Feng, M.; Tang, B.; Jiang, X. Tetrahedron Lett. 2014, 55, 7147. (d) Garcia-Urdiales, E.; Alfonso, I.; Gotor, V. Chem. Rev. 2011, 111, PR110. (e) Hoffmann, R. W. Angew. Chem. Int. Ed. 2003, 42, 1096. (f) Willis, M. C. J. Chem. Soc., Perkin Trans. 1 1999, 1765. (g) Magnuson, S. R. Tetrahedron 1995, 51, 2167. (h) Ward, R. S. Chem. Soc. Rev. 1990, 1.

(6) We talk about local symmetry when a significant portion of the target molecule presents an apparent symmetry, as an example, see: Candy, M.; Tomas, L.; Parat, S.; Héran, V.; Bienaymé, H.; Pons, J.-M.; Bressy, C. Chem. Eur. J. 2012, 18, 14267.

(7) Laumen, K.; Scheinder, M. Tetrahedron Lett. 1984, 25, 5875.

(8) (a) Vigneron, J. P.; Dhaenes, M.; Horeau, A. Tetrahedron 1973 29,1055 . For the expression concerning multiple enantioselective reactions, see: (b) Rautenstrauch, V. Bull. Soc. Chim. Fr. 1994, 131, 515.

(9) For a review, see: Glueck, D. Catal. Sci. Technol. 2011, 1, 1099.

(10) Merad, J.; Borkar, P.; Bouyon-Yenda, T.; Roux, C.; Pons, J.-M.; Parrain, J.-L.; Chuzel, O.; Bressy, C. Org. Lett. 2015, 17, 2118.

(11) Trost, B. M. Science (Washington, D. C.) 1991, 254, 1471.

(12) Wender, P. A.; Verma, V. A.; Paxton, T. J.; Pillow, T. H. Acc. Chem. Res. 2008, 41, 40.

(13) Burns, N. Z.; Baran, P. S.; Hoffmann, R. W. Angew. Chem. Int. Ed. 2009, 48, 2854

(14) Walker, R. P.; Faulkner, D. J.; Van Engen, D.; Clardy, J. J. Am. Chem. Soc. 1981, 103, 6772.

(15) Baran, P. S.; Zografos, A. L.; O’Malley, D. P. J. Am. Chem. Soc. 2004, 126, 3726.

(16) Baran, P. S.; Li, K.; O'Malley, D. P.; Mitsos, C. Angew. Chem. Int Ed. 2006, 45, 249 .

(17) Laing, J.; McCulloch, A. W.; Smith, D. G.; McInnes, A. G. Can. J. Chem. 1971, 49, 574.

(18) Baran, P. S.; O'Malley, D. P.; Zografos, A. L. Angew. Chem. Int. Ed. 2004, 43, 2674.

(19) For a review, see: Bermejo, A.; Figadère, B.; Zafra-Polo, M.-C.; Barrachina, I.; Estornell, E.; Cortes, D. Nat. Prod. Rep. 2005, 22, 269.

(20) For total syntheses of cis-solamin, see: (a) Makabe, H.; Hattori, Y.; Tanaka, A.; Oritani, T. Org. Lett. 2002, 4, 1083. (b) Cecil, A. R. L.; Brown, R. C. D. Org. Lett. 2002, 4, 3715. (c) Konno, H.; Okuno, Y.; Makabe, H.; Nosaka, K.; Onishi, A.; Abe, Y.; Sugimoto, A.; Akaji, K. Tetrahedron Lett. 2008, 49, 782.

(21) Göksel, H.; Stark, C. B. W. Org. Lett. 2006, 8, 3433.

(22) Roth, S.; Göhler, S.; Cheng, H.; Stark, C. B. W. Eur. J. Org. Chem. 2005, 4109.

(23) Trost, B. M.; Toste, F. D. Tetrahedron Lett. 1999, 40, 7739.

(24) Isolation: (a) Kunze, B.; Jansen, R.; Höfle, G.; Reichenbach, H. J. Antibiot. 1994, 47, 881. (b) Jansen, R.; Washausen, P.; Kunze, B.; Reichenbach, H.; Höfle, G. Eur. J. Org. Chem. 1999, 1085.

(25) Previous total syntheses: (a) Feutrill, J. T.; Lilly, M. J.; Rizzacasa, M. A. Org. Lett. 2000, 2, 3365. (b) Chakraborty, T. K.; Jayaprakash, S. Tetrahedron Lett. 2001, 42, 497. (c) Chakraborty,
T. K.; Jayaprakash, S.; Laxman, P. Tetrahedron 2001, 57, 9461. (d) Dias, L. C.; de Oliveira, L. G. Org. Lett. 2001, 3, 3951 (e) Sirasani, G.; Paul, T.; Andrade, R. B. J. Org. Chem. 2008, 73 , 6386. (f) Gillis, E. P.; Burke, M. D. J. Am. Chem. Soc. 2008, 130 14084. For a general review on crocacin syntheses see: (g) Andrade, R. B. Org. Prep. Proced. Int. 2009, 41, 359. Later total syntheses: (h) Cheng, M.; Roush, W. R. Org. Lett. 2012, 14, 1880. (i) Pasqua, A. E.; Ferrari, F. D.; Hamman, C.; Liu, Y.; Crawford, J. J.; Marquez, R. J. Org. Chem. 2012, 77, 6989. (j) Infante-Rodriguez, C.; Domon, L.; Breuilles, P.; Uguen, D. Bull. Chem. Soc. Jpn. 2015, 88, 308.

(26) Candy, M.; Audran, G.; Bienaymé, H.; Bressy, C.; Pons, J. M. Org. Lett. 2009, 11, 4950.

(27) Candy, M.; Audran, G.; Bienaymé, H.; Bressy, C.; Pons, J. M. J. Org. Chem. 2010, 75, 1354.

(28) (a) Lubineau, A.; Bouchain, G. Tetrahedron Lett. 1997, 38, 8031. (b) Lautens, M.; Bouchain, G. Org. Synth. 2002, 79, 251.

(29) For a review, see: (a) Saicic, R. N. Tetrahedron 2014, 70, 8183. (b) Young, I. S.; Baran, P. S. Nat. Chem. 2009, 1, 193. (c) Hoffmann, R. W. Synthesis 2006, 3531.

(30) (a) Schreiber, S. L.; Goulet, M. T.; Schulte, G. J. Am. Chem. Soc. 1987, 109, 4718. (b) Schreiber, S. L.; Goulet, M. T. J. Am. Chem. Soc. 1987, 109, 8120. (c) Ref. 34.

(31) Lebsack, A. D.; Link, J. T.; Overman, L. E.; Stearns, B. A. J. Am. Chem. Soc. 2002, 124, 9008.

(32) Libot, F.; Miet, C.; Kunesch, N.; Poisson, J. E.; Pusset, J.; Sévenet, T. J. Nat. Prod. 1987, 50, 468 .

(33) (a) Overman, L. E.; Larrow, J. F.; Stearns, B. A.; Vance, J. M. Angew. Chem. Int. Ed. 2000, 39, 213. The Willis group described recently a straightforward synthesis of meso-chimonanthine in only 3 steps from tryptamine: (b) Snell, R. H.; Woodward, R. L.; Willis, M. C. Angew. Chem. Int. Ed. 2011, 50, 9116.

(34) For a review, see: Poss, C. S.; Schreiber, S. L. Acc. Chem. Res. 1994, 27, 9 .

(35) (a) Ashimori, A.; Bachand, B.; Calter, M. A.; Govek, S. P.; Overman, L. E. J. Am. Chem. Soc. 1998, 120, 6488. (b) Oestreich, M.; Dennison, P. R.; Kodanko, J. J.; Overman, L. E. Angew. Chem. Int. Ed. 2001, 40, 1439

(36) McManus, H.; Fleming, M. J.; Lautens, M. Angew. Chem. Int. Ed. 2007, 46, 433.

(37) Probst, J. M. Ann. Pharm. (Lemgo, Ger.) 1839, 29, 113.

(38) Enquist, J. A. Jr.; Stoltz, B. M. Nature (London) 2008, 453, 1228.

(39) For review, see: Anstiss, M.; Holland, J.; Nelson, A.; Titchmarsh, J. Synlett 2003, 1213.

(40) For reviews, see: (a) Mohr, J. T.; Ebner, D. C.; Stoltz, B. M. Org Biomol. Chem. 2007, 5, 3571. (b) Bhat, V.; Welin, E. R.; Guo, X.; Stoltz, B. M. Chem. Rev. 2017, DOI: 10.1021/acs.chemrev.6b00731.

(41) Mohr, J. T.; Behenna, D. C.; Harned, A. M.; Stoltz, B. M. Angew. Chem. Int. Ed. 2005, 44, 6924.

(42) Virolleaud, M.-A.; Bressy, C.; Piva, O. Tetrahedron Lett. 2003, 44, 8081.

(43) Kim, K. E.; Stoltz, B. M. Org. Lett. 2016, 18, 5720.

(44) Mercern, J. A. M.; Cohen, C. M.; Shuken, S. R.; Wagner, A. M.; Smith, M. W.; Moss, F. R. III; Vahala, R.; Gonzalez-Martinez, A.; Boxer, S. G.; Burns, N. Z. J. Am. Chem. Soc. 2016, 138, 15845

(45) (a) Mascitti, V.; Corey, E. J. J. Am. Chem. Soc. 2004, 126, 15664. (b) Mascitti, V.; Corey, E. J. J. Am. Chem. Soc. 2006, 128, 3118.

(46) Liu, W.; Groves, J. T. J. Am. Chem. Soc. 2010, 132, 12847.

(47) Guisán-Ceinos, M.; Parra, A.; Martín-Heras, V.; Tortosa, M. Angew. Chem. Int. Ed. 2016, 55, 6969.

(48) Zweifel, G.; Fisher, R. P.; Snow, T. J.; Whitney, C. C. J. Am. Chem. Soc. 1971, 93, 6309 
(49) Chandler, C. L.; List, B. J. Am. Chem. Soc. 2008, 130, 6737.

(50) Nozoe, S.; Furukawa, J.; Sankawa, U.; Shibata, S. Tetrahedron Lett. 1976, 17, 195.

(51) (a) Hua, D. H.; Venkataraman, S.; Sinai-Zingde, G. J. Am. Chem. Soc. 1985, 107, 4088. (b) Weinges, K.; Reichert, H.; Huber-Patz, U.; Irngartinger, H. Liebigs Ann. Chem. 1993, 403. (c) Banwell, M. G.; Edwards, A. J.; Harfoot, G. J.; Jolliffe, K. A. Tetrahedron 2004, 60, 535.

(52) Del Zotto, A.; Baratta, W.; Verardo, G.; Rigo, P. Eur. J. Org. Chem. 2000, 2795.

(53) Cai, X. H.; Du, Z. Z.; Luo, X. D. Org. Lett. 2007, 9, 1817

(54) Gerfaud, T.; Xie, C.; Neuville, L.; Zhu, J. Angew. Chem. Int. Ed. 2011, 50, 3954.

(55) Oh, S. H.; Rho, H. S.; Lee, J. W.; Lee, J. E.; Youk, S. H.; Chin, J.; Song, C. E. Angew. Chem. Int. Ed. 2008, 47, 7872.

(56) Nicolaou, K. C.; Claremon, D. A.; Papahatjis, D. P. Tetrahedron Lett. 1981, 22, 4647.

(57) (a) Chen, C.-Y.; Lieberman, D. R.; Larsen, R. D.; Verhoeven, T. R.; Reider, P. J. J. Org. Chem. 1997, 62, 2676. (b) Jia, Y. X.; Zhu, J. Synlett 2005, 2469. (c) Jia, Y. X.; Zhu, J. J. Org. Chem. 2006, 71, 7826.

(58) Horikawa, Y.; Watanabe, M.; Fujiwara, T.; Takeda, T. J. Am. Chem. Soc. 1997, 119, 1127.

(59) Isolation: Yin, J.; Kouda, K.; Tezuka, Y.; Trans, Q. L.; Miyahara, T.; Chen, Y.; Kadota, S. Planta Med. 2004, 70, 54
(60) Total syntheses of (-)-diospongin A: (a) Chandrasekhar, S.; Shyamsunder, T.; Prakash, J. S.; Prabhakar, A.; Jagadeesh, B. Tetrahedron Lett. 2006, 47, 47. (b) Bressy, C.; Allais, F.; Cossy, J. Synlett 2006, 3455. (c) Jennings, M. P.; Sawant, K. B. J. Org. Chem. 2006, 71, 7911. (d) Yadav, J. S.; Padmavani, B.; Reddy, B. V. S.; Venugopal, C.; Rao, A. B. Synlett 2007, 2045. (e) Bates, R. W.; Song, P. Tetrahedron 2007, 63, 4497. (f) Kawai, N.; Hande, S. M.; Uenishi, J. Tetrahedron 2007, 63, 9049. (g) Wang, H.; Shuhler, B. J.; Xian, M. Synlett 2008, 2651. (h) Sabitha, G.; Padmaja, P. Helv. Chim. Acta 2008, 91, 2235. (i) Kumaraswamy, G.; Ramakrishna, G.; Naresh, P.; Jagadeesh, B.; Sridhar, B. J. Org. Chem. 2009, 74 8468. (j) Anada, M.; Washio, T.; Watanabe, Y.; Takeda, K.; Hashimoto, S. Eur. J. Org. Chem. 2010, 6850. (k) Kumar, R. N.; Meshram, H. M. Tetrahedron Lett. 2011, 52, 1003. (1) Stefan, E.; Nalin, A. P.; Taylor, R. E. Tetrahedron 2013, 69, 7706. (m) Zuniga, A.; Perez, M.; Gandara, Z.; Fall, A.; Gomez, G.; Fall, Y. ARKIVOC 2015, (vii), 195.

(61) For reviews, see: (a) Merad, J.; Pons, J.-M.; Chuzel, O.; Bressy, C. Eur. J. Org. Chem. 2016, 5589. (b) Birman, V. B. Aldrichimica Acta 2016, 49, 23.

(62) (a) Birman, V. B.; Jiang, H.; Li, X. Org. Lett. 2007, 9, 3237. (b) Roux, C.; Candy, M.; Pons, J.-M.; Chuzel, O.; Bressy, C. Angew. Chem. Int. Ed. 2014, 53, 766. 